\title{
The Growth Cone Cytoskeleton in Axon Outgrowth and Guidance
}

\author{
Erik W. Dent ${ }^{1}$, Stephanie L. Gupton ${ }^{2,3}$, and Frank B. Gertler ${ }^{2}$ \\ ${ }^{1}$ Department of Anatomy, University of Wisconsin-Madison, Madison, Wisconsin 53706 \\ ${ }^{2}$ The Koch Institute for Integrative Cancer Research at MIT, Massachusetts Institute of Technology, Cambridge, \\ Massachusetts 02139 \\ ${ }^{3}$ Department of Cell and Developmental Biology, University of North Carolina-Chapel Hill, Chapel Hill, \\ North Carolina 27599 \\ Correspondence: fgertler@mit.edu
}

\begin{abstract}
Axon outgrowth and guidance to the proper target requires the coordination of filamentous (F)-actin and microtubules (MTs), the dynamic cytoskeletal polymers that promote shape change and locomotion. Over the past two decades, our knowledge of the many guidance cues, receptors, and downstream signaling cascades involved in neuronal outgrowth and guidance has increased dramatically. Less is known, however, about how those cascades of information converge and direct appropriate remodeling and interaction of cytoskeletal polymers, the ultimate effectors of movement and guidance. During development, much of the communication that occurs between environmental guidance cues and the cytoskeleton takes place at the growing tip of the axon, the neuronal growth cone. Several articles on this topic focus on the "input" to the growth cone, the myriad of receptor types, and their corresponding cognate ligands. Others investigate the signaling cascades initiated by receptors and propagated by second messenger pathways (i.e., kinases, phosphatases, GTPases). Ultimately, this plethora of information converges on proteins that associate directly with the actin and microtubule cytoskeletons. The role of these cytoskeletal-associated proteins, as well as the cytoskeleton itself in axon outgrowth and guidance, is the subject of this article.
\end{abstract}

\begin{abstract}
$A^{s}$ evidenced by other articles on this topic, Aour understanding of the cues, receptors, and signaling events underlying axon outgrowth and guidance has grown dramatically in recent years. Here, we focus on recent research involving cytoskeletal dynamics downstream of guidance receptor signaling that has begun to unravel the mechanisms underlying guided growth cone movement during development. We begin by covering how growth cone morphology changes during outgrowth and
\end{abstract}

guidance. Since cytoskeletal dynamics underlie changes in growth cone morphology, we discuss where different cytoskeletal polymers reside in the growth cone and what forms of dynamic reorganization they undergo. We then present a description of selected actin- and microtubule-associated proteins that have been identified in developing neurons and discuss how they may function in axon outgrowth and guidance. Finally, we present a working model of how growth cones integrate multiple signaling

Editors: Marc Tessier-Lavigne and Alex L. Kolodkin

Additional Perspectives on Neuronal Guidance available at www.cshperspectives.org

Copyright (C) 2011 Cold Spring Harbor Laboratory Press; all rights reserved; doi: 10.1101/cshperspect.a001800

Cite this article as Cold Spring Harb Perspect Biol 2011;3:a001800 
E.W. Dent et al.

cascades to produce functionally useful output, and highlight some of the outstanding questions and challenges that face the field of growth cone cytoskeletal biology.

\section{GROWTH CONE FORM AND FUNCTION}

The axonal growth cone is the highly dynamic "fan-shaped" distal tip of the axon. Growth cones assume many shapes and sizes and appear to probe their environment constantly by extending and retracting membrane protrusions (Dent and Gertler 2003; Lowery and Van Vactor 2009). These protrusions take the form of tapered finger-like projections, called filopodia, and flat sheet-like protrusions called lamellipodia or veils (Fig. 1). When viewed in time-lapse microscopy, filopodia and lamellipodia are often extremely dynamic: They can form, extend, or withdraw within seconds to minutes. Filopodia and lamellipodia comprise the peripheral regions of the growth cone. This dynamic periphery transitions to a more stable central region of the growth cone. Although the central region exhibits less plasma membrane dynamics than the periphery, there is substantial molecular motion within this region, including the constant shuttling of organelles and vesicles. The
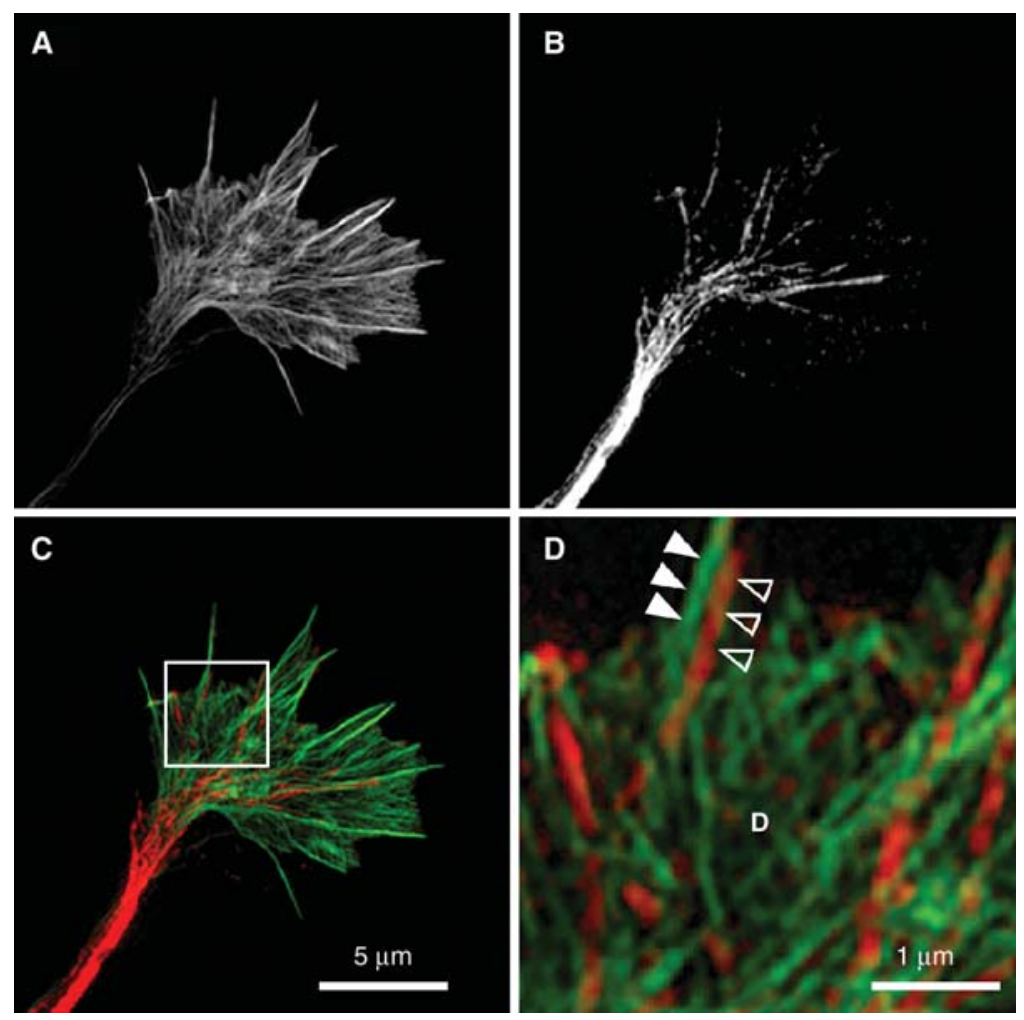

Figure 1. F-actin and microtubule distribution in a hippocampal growth cone. $(A)$ In this typical mouse hippocampal growth cone, labeled with fluorescent phalloidin, the F-actin is concentrated in filopodia (bundled F-actin) and lamellipodia (meshwork of F-actin), with relatively little F-actin in the axon shaft. (B) Microtubules, labeled with an antibody to tyrosinated tubulin, are concentrated as a bundle in the axon shaft but also splay apart in the growth cone, extending into distal peripheral regions. $(C)$ A false-color overlay of images in $A$ and $B$. Microtubules are in red and F-actin is in green. $(D)$ A magnified view of the boxed region in $C$. Note the close apposition of an F-actin bundle (closed arrowheads) at the base of a filopodium and an individual microtubule (open arrowheads). At this magnification, the dendritic (D) actin meshwork can also be discerned. 
The Growth Cone Cytoskeleton in Axon Outgrowth and Guidance

central region of the growth cone then transitions into the cylindrical axon shaft.

In a still micrograph, these regions of the distal axon can be identified, but it is important to realize that these domains are transient. As a consequence of outgrowth, the growth cone constantly undergoes dynamic changes in its structure, allowing it to lay down new regions of axon along the path to its target as it moves. Axon outgrowth results from progress through three stages: protrusion, engorgement, and consolidation. Protrusion is the extension of new membrane at the edges of the growth cone, driven by filamentous actin (F-actin) polymerization. Engorgement results from microtubule (MT)-driven transport of membranous organelles and vesicles into the otherwise actin-dominated peripheral regions. Consolidation results from the contraction and stabilization of the proximal growth cone into a cylindrical axon shaft, accompanied by the bidirectional movement of organelles and vesicles. These stages were first described at the morphological level using differential interference contrast (DIC) microscopy (Goldberg and Burmeister 1986). However, as we describe below, these stages result from specific cytoskeletal changes that occur in discrete locations within the growth cone. In addition to these stages of outgrowth, growth cones also undergo cycles of pausing and retraction that engage other cytoskeletal changes. Throughout this article, we discuss how these changes in output are triggered by guidance cues received at the growth cone or along the axon shaft.

\section{ACTIN DYNAMICS IN GROWTH CONE PROTRUSION}

Growth cone protrusion and motility is driven primarily by the cyclical polymerization and depolymerization of actin filaments (Fig. 2). Actin dynamics are necessary for directed axonal outgrowth, but not necessarily for growth

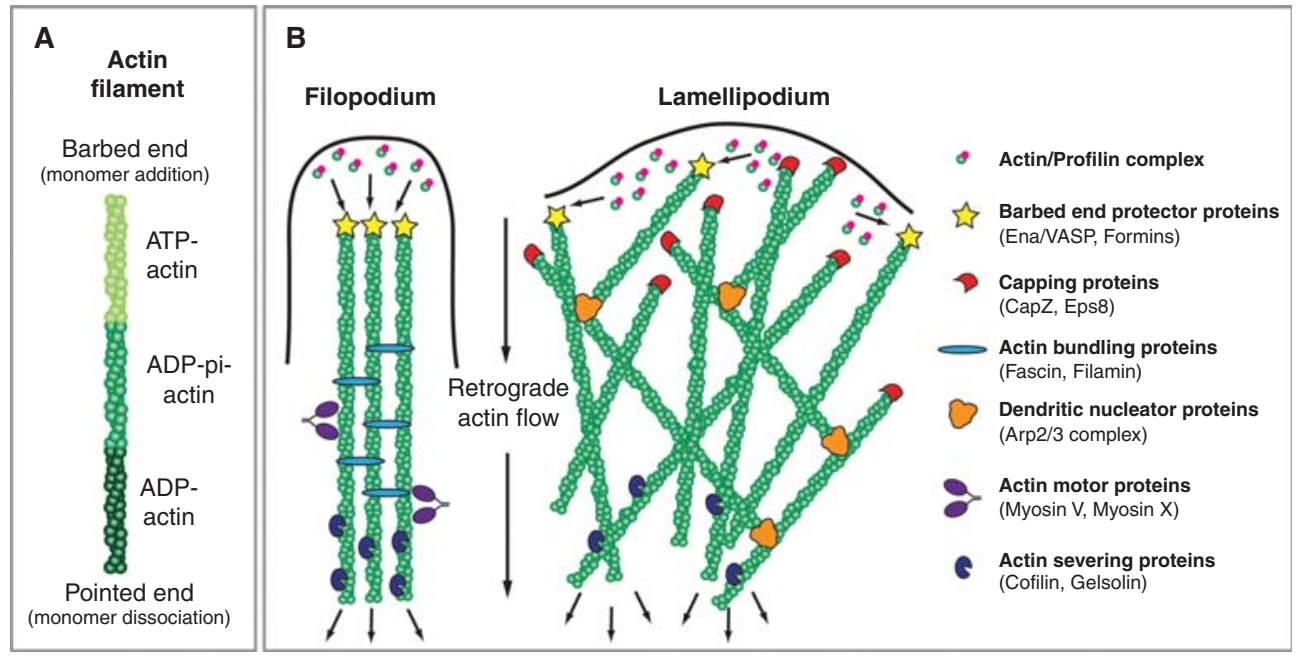

Figure 2. Structural characteristics of F-actin and actin-associated proteins. (A) Actin filaments are polar polymers composed of a barbed end, where the bulk of actin monomer addition occurs, and a pointed end, where dissociation of actin monomers occur. The nucleotide state of the actin changes as the filaments age $(\mathrm{ATP} \rightarrow \mathrm{ADPpi} \rightarrow \mathrm{ADP})$. (B) F-actin in a filopodium forms bundles due to the action of bundling proteins. Actin monomers add onto existing filaments at the tip of the filopodium through the action of barbed-end binding proteins. Actin filaments are constantly undergoing retrograde flow (large vertical arrows) and are disassembled near their pointed ends by severing proteins. Motor proteins use the bundled F-actin to transport cargo both anterogradely and retrogradely. In contrast, F-actin in the lamellipodium forms a dendritic network through the action of dendritic nucleator proteins and capping proteins. Addition of actin monomers also occurs near the membrane, and disassembly occurs more proximally in the growth cone. 
E.W. Dent et al.

cone translocation, per se. Many studies, both in culture (Marsh and Letourneau 1984; Lafont et al. 1993; Dent and Kalil 2001) and within model organisms (Bentley and ToroianRaymond 1986; Chien et al. 1993; Kaufmann et al. 1998), have shown that neurons treated with agents that depolymerize F-actin are still capable of elongation. Such neurons, however, generally cannot respond to guidance cues and become misrouted in vivo or form axonal loops in culture, presumably because they cannot change direction once they start turning. Importantly, F-actin dynamics appear to be particularly important for growth cone exploration of the environment.

As in other cell types, G-actin is added onto the free barbed ends of filaments located at the tips of filopodia (Mallavarapu and Mitchison 1999) and lamellipodia (Symons and Mitchison 1991). By labeling actin filaments within living growth cones, either with fluorescent monomer (EGFP-actin or by microinjecting G-actin coupled to a dye) or fluorescently labeled phalloidin, F-actin is found to be in a steady retrograde flow from the leading edge to the center of the growth cone. Elegant studies from the Forscher lab have shown that this retrograde Factin flow is a result of both myosin-II-driven actin transport and a pushing force that actin exerts on the peripheral membrane as it is polymerizing (Lin et al. 1996; Zhang et al. 2003; Medeiros et al. 2006). The balance between the rate of polymerization and retrograde flow determines if the growth cone extends or withdraws protrusions: If the polymerization rate exceeds retrograde flow (which averages $3-6 \mu \mathrm{m} / \mathrm{min}$ ), then the growth cone protrudes. If the polymerization rate is balanced with the velocity of retrograde flow, then the membrane remains stationary. Thus, it would be expected that if myosin activity is decreased, retrograde flow would decrease and protrusion would increase. To a certain extent this does happen, but the protrusions tend to be unstable and random (Medeiros et al. 2006). Importantly, when connection to the underlying substratum is increased by tighter coupling between the actin cytoskeleton and transmembrane adhesion receptors, retrograde flow slows and the balance shifts to polymerization-driven protrusion (Suter and Forscher 2001). Thus, retrograde actin flow tends to act as a background activity upon which other factors can act.

Interestingly, the motor protein myosin-II has also been shown to be important for severing actin filaments in the proximal "transition zone" of the growth cone that demarcates the border between the growth cone's actin-rich periphery and the MT-rich central region (Medeiros et al. 2006). Myosin-II does not sever actin filaments directly, but rather exerts contractile forces on anti-parallel F-actin that contracts the actin meshwork to a point that it breaks the filaments into smaller pieces; these undergo rapid depolymerization in the transition zone. There are also a number of known actin-severing proteins that likely have important roles in severing actin filaments in the transition zone (Fig. 2), but the potential requirements for two prominent severing proteins found in this region, gelsolin ( $\mathrm{Lu}$ et al. 1997) and cofilin (Pak et al. 2008), have yet to be demonstrated.

Driven by dynamic remodeling of the actin cytoskeleton, lamellipodial and filopodial protrusions underlie growth cone motility and guidance. It is widely assumed that repulsive growth cone turning arises from disruption and loss of F-actin superstructures and actomyosin contraction, while attractive growth cone turning entails asymmetrical incorporation of actin on the side of the growth cone closest to the chemoattractant. In support of the aforementioned model for growth cone chemoattraction, Marsick and colleagues recently reported that application of chemoattractive guidance cues NGF or netrin 1 to dorsal root ganglia (DRG) induced increased protrusion, F-actin accumulation, and increased barbed end density on the side of the growth cone nearest the source of the gradient (Marsick et al. 2010). It is important, however, to note that there are relatively few detailed, high-resolution studies of cytoskeletal and morphological dynamics of growth cones turning toward or away from guidance cues (e.g., Dent et al. 2004; Suter et al. 2004; Brown and Bridgman 2009; Brown et al. 2009; Marsick et al. 2010). Therefore, it remains unclear 
The Growth Cone Cytoskeleton in Axon Outgrowth and Guidance

whether all attractive and repulsive events involve analogous cytoskeletal and shape changes.

An additional level of complexity in understanding the function of cytoskeletal machinery during guidance is that individual components likely act in a context-dependent fashion, influenced by the signaling status in the growth cone, the repertoire of cytoskeletal proteins present in the growth cone, and adhesive interactions. For example, the actin severing/depolymerizing protein cofilin is required for axon extension in hippocampal neurons (Garvalov et al. 2007) and dorsal root ganglia neurons (Endo et al. 2003), but likely not in cerebellar granular neurons (Tahirovic et al. 2010). In addition, cofilin activity has been implicated in both attractive (Marsick et al. 2010) and repulsive (Wen et al. 2007) guidance responses. Moreover, in Xenopus spinal neurons, the requirements for cofilin function in response to BMP7 are thought to change as neurons mature: In 4-8 hour neurons, axons are attracted to BMP7, and cofilin must be inactive for this response; after overnight culture, BMP7 repels axons, and this response requires asymmetric cofilin activity in the portion of the growth cone exposed to the higher BMP7 concentration (Wen et al. 2007). Despite its role in BMP7 repulsion, growth cone collapse induced by Sema3A requires inactivation of cofilin (Aizawa et al. 2001). Therefore, it may not be possible to extrapolate the mechanism of turning or collapse from one cue to another, from one neuron type to another, or the role of particular cytoskeletal proteins in different contexts. There may also be speciesspecific differences that affect how certain cytoskeletal proteins are utilized (Marsick et al. 2010). Such context-dependent functions are reminiscent of the ways in which guidance cues and their cognate receptors can elicit distinct responses.

In this article, we focus on how actin dynamics affect membrane protrusions and generate structures that interact with the MT cytoskeleton. It is clear, however, that actin-dependent or actin-influenced processes, such as adhesion, membrane trafficking, and endo/exocytosis, play equally important roles in growth cone formation, motility, and guidance responses (e.g.,
Jurney et al. 2002; Suh et al. 2004; Tojima et al. 2007; Kolpak et al. 2009; Hines et al. 2010; Tojima et al. 2010). While space constraints preclude coverage of these topics, the reader should bear in mind that some of the proteins discussed below might exert their effects on guidance by influencing adhesion dynamics and membrane/vesicle transport.

\section{MICROTUBULE DYNAMICS IN AXON GUIDANCE}

Although actin and actin-associated proteins are usually the first cytoskeletal proteins that come to mind when one considers axon guidance, a number of studies implicate microtubules (MTs) directly in growth cone steering. The idea that MTs are involved in guidance decisions was first suggested by pioneering studies from the Kirschner laboratory, showing in living neurons that fluorescently labeled MTs were capable of exploring the growth cone periphery, and that the orientation of MTs often predicted the direction of outgrowth (Sabry et al. 1991; Tanaka and Kirschner 1995). Further work from several laboratories confirmed and extended these findings by showing that the dynamic pool of MTs (identified by a post-translational modification that adds a c-terminal tyrosine residue-referred to as tyrosinated MTs) was key for either directed outgrowth toward a target or chemorepulsion at two substrate boundaries (Lin and Forscher 1993; Lin and Forscher 1995; Williamson et al. 1996; Challacombe et al. 1997). Nevertheless, the general perception remained that actin filaments initiated that change in the direction of growth and MTs followed their lead.

However, a more recent study showed that simply changing MT dynamics by locally applying, or photo-uncaging, MT-specific drugs on one side of a growth cone was sufficient to induce growth cone turning (Buck and Zheng 2002). These results led the authors to propose that MTs were indeed playing an instructive role in growth cone guidance, since simply changing MT dynamics asymmetrically was sufficient to induce growth cone turning. Nevertheless, these results do not mitigate the role 
E.W. Dent et al.

that actin plays in growth cone turning. Indeed, growth cone turning induced by taxol application can be abrogated by inclusion of nanomolar concentrations of cytochalasin D, a drug that caps actin filaments (Buck and Zheng 2002). These results indicate that even if extracellular cues signal directly to MTs, the output of the response, growth cone turning, is likely to proceed through changes in the actin cytoskeleton.

These studies raise an intriguing question: Could spatially and temporally restricted presentation of guidance cues regulate MT dynamics and stability directly to give rise to growth cone turning? To answer this question, we first have to understand what effect guidance cues have on microtubule dynamics. However, quantifying MT dynamics in neuronal growth cones is difficult. MTs constantly polymerize and depolymerize throughout the growth cone peripheral domain due to a behavior inherent in the structure of these polymers termed " $\mathrm{dy}$ namic instability." Growth cones occupy relatively small areas and expand and contract, making imaging MT dynamics challenging. It is a daunting task to image these dynamics for extended periods of time while locally applying guidance cues. Thus, there have been no studies to date that have imaged MT dynamics in growth cones during local application of a guidance cue. However, MT dynamics have been imaged after bath application of several guidance cues. In one study, Sema3a was bath applied to large, paused growth cones from cultured cortical neurons (Dent et al. 2004). MTs rapidly lost their dynamic behavior and collapsed back onto the central region of the growth cone. In this study, netrin was shown to induce opposite changes in MTs, causing increased splaying of MTs in the growth cone and axon shaft. However, the effect of netrin was only documented in fixed growth cones. A more recent study has shown that bath application of Wnt3a induces MTs to lose directionality and polymerize perpendicular to the direction of growth cone translocation (Purro et al. 2008). Over time, this behavior results in MT looping, growth cone enlargement, and pausing. These studies indicate that MTs are sensitive to guidance cues, but further research is necessary to understand how MT dynamics are directly or indirectly regulated by such cues.

Additionally, there have been a number of studies of MT dynamics in large Aplysia growth cones that provide insight into how MT dynamics may be regulated in growth cones during guidance decisions (Suter and Forscher 2000). These studies by the Forscher and Suter laboratories include imaging of MT and actin dynamics at high temporal and spatial resolution while conducting a localized adhesion-based assay. In this assay, a polystyrene bead is coated with a cell adhesion molecule (apCAM) and positioned on top of an adherent and well-spread growth cone. By restraining this bead with a microneedle, these researchers were able to show an ensuing stereotyped series of events (Suter et al. 1998; Suter et al. 2004; Lee and Suter 2008; Schaefer et al. 2008). Normally, the actin in the growth cone undergoes constitutive retrograde flow. As the apCAM bead engages receptors on the growth cone, an actin scaffold begins to accumulate near the plasma membrane underlying the bead. This actin matrix couples to the cell adhesion complex, engaging a "clutch" type mechanism. During this time, termed the latency phase, exploratory MTs polymerize and are transported anterogradely toward the actin matrix under the bead. Progressive coupling of the bead to the growth cone, forming a mature adhesion site, instigates a loss of actin retrograde flow behind the bead and possibly an increase in severing and/or unbundling of the actin. Clearing of the actin behind the bead allows for more microtubule invasion toward the bead and potential capture at the adhesion sight. This traction period (Lee and Suter 2008) or growth phase (Schaefer et al. 2008) is accompanied by protrusion of lamellipodia and filopodia beyond the bead. Presumably, this sequence of stereotyped cytoskeletal behaviors would repeat as soon as the growth cone made another productive adhesion in a more distal region of the growth cone.

Using this methodology, one group stresses that actin arcs, the actomyosin contractile network in the transition region of the growth cone, are important for guiding MTs to the bead adhesion site (Schaefer et al. 2008). The 
other group indicates that a critical aspect underlying the ability of MTs to target the bead, and presumably induce a new axis of outgrowth, is the uncoupling of putative MT-actin linker molecules (Lee and Suter 2008). This restricted bead assay provides essential knowledge about cytoskeletal interactions underlying adhesion-based growth. However, many guidance cues are not cell-adhesion molecules. Thus, this assay may be better defined as a neurite growth model (Schaefer et al. 2008), rather than a model for guidance (Lee and Suter 2008), per se. An important question for future experiments will be to determine if local application of guidance cues to the growth cone induces the same types of cytoskeletal behaviors in actively translocating growth cones, as are seen in these large, paused, Aplysia growth cones.

\section{ACTIN-ASSOCIATED PROTEINS IN AXON GUIDANCE}

The exquisite control of actin nucleation, elongation, depolymerization, bundling, and contraction necessary to shape the growth cone and enable dynamic responses to a plethora of extracellular cues is mediated by a complex repertoire of actin accessory proteins found in many cell types (see Table 1 and Fig. 2). More than 100 such accessory proteins are used by eukaryotic cells to nucleate filaments, control filament length, bundle or cross-link filaments, disassemble filament networks, and maintain a pool of actin monomers (Pollard and Cooper 2009). While an increasing number of these actin accessory proteins have been identified in neurons, it is likely that the abundance of various classes of actin regulators differs according to cell type, and it is clear that the relative levels of some key types of actin regulatory proteins in the growth cone differ from the stoichiometries found in systems that are commonly used to analyze the regulation of actin dynamics (Strasser et al. 2004). Thus, an exquisite balance of actin accessory proteins likely contributes to the distinctive morphology of growth cones. Many actin binding proteins in the growth cone regulate lamellipodia and filopodia dynamics, axon guidance, or both, but how guidance cues orchestrate cytoskeletal remodeling by the many proteins within the growth cone to elicit the proper response remains largely unknown. While the list of known actin-associated proteins is expansive and many are expressed in the developing nervous system, relatively few have been implicated in axon guidance. Here, we consider actin-associated proteins that have been specifically implicated in growth cone guidance.

\section{Barbed-end Binding Proteins}

This group of proteins associates with actin filament barbed ends. Some cap barbed ends, terminating filament elongation. Other barbedend binding proteins protect the filament end from polymerization-terminating capping proteins, and in some cases alter the rate of Gactin incorporation at the filament end. As in other cells, most filaments within growth cones are oriented with their barbed ends toward the front edge of lamellipodial veils and filopodial tips, sites where rapid responses to guidance cues are likely essential for proper navigation (Fig. 2).

\section{Ena/VASP Proteins}

The Ena/VASP proteins were the first examples of barbed-end binding proteins implicated in axon guidance (Drees and Gertler 2008). There are three vertebrate Ena/VASP paralogs (Mena, VASP, and EVL), while Drosophila and C. elegans each contain a single ortholog, Enabled (Ena) and UNC-34, respectively. While Ena/VASP proteins are found in many cell types, they are highly expressed in the developing nervous system, where they concentrate in the filopodial tips of growth cones as well as the leading edge of lamellipodia (Lanier et al. 1999), two structures rich in elongating barbed ends. The localization of Ena/VASP proteins to these structures, as well as interactions with signaling proteins, is controlled in part by protein-protein interactions between the conserved EVH1 (Ena/ VASP homology 1) domain and proteins that contain EVH1-binding motifs (Niebuhr et al. 1997; Ball et al. 2002). At least two molecules involved in axon guidance contain functional EVH1-binding sites: Robo/Sax3 (Bashaw et al. 
E.W. Dent et al.

Table 1. Actin Regulators.

\begin{tabular}{|c|c|c|c|}
\hline Protein Family & Guidance Assay & Potential Guidance Pathways & References \\
\hline \multicolumn{4}{|c|}{ Barbed-end Binding Proteins } \\
\hline Ena/VASP & I (Mm, Dm, Ce $)$ & $\begin{array}{l}\text { Netrin and SLIT pathway } \\
\text { Dm Ce }\end{array}$ & $\begin{array}{l}\text { (Bashaw et al. 2000; Gitai et al. } \\
\text { 2003; Forsthoefel et al. 2005; } \\
\text { Chang et al. 2006) }\end{array}$ \\
\hline DAAM & I (Dm) & $\begin{array}{l}\text { Misrouted axons, broken } \\
\text { commissures }\end{array}$ & (Matusek et al. 2008) \\
\hline \multicolumn{4}{|c|}{ F-actin Binding/Bundling Proteins } \\
\hline ERM proteins & C, C-R & Sema Pathway & (Mintz et al. 2008) \\
\hline Unc115/Ablim & $\mathbf{I}(\mathrm{Ce})$ & VD DD motor neurons & (Lundquist et al. 1998) \\
\hline GAP43 & I (MR), C & $\begin{array}{l}\text { Retinal, callosal, } \\
\text { thalamocortical }\end{array}$ & $\begin{array}{l}\text { (Maier et al. 1999; Zhu and Julien } \\
\text { 1999; Shen et al. 2002) }\end{array}$ \\
\hline Unc-44/Ankryin & $\mathbf{I}(\mathrm{Ce})$ & Netrin pathway & (Colavita and Culotti 1998) \\
\hline ß-Spectrin & $\mathbf{I}(\mathrm{Dm})$ & midline defects & $\begin{array}{l}\text { (Hummel et al. 1999; Williams } \\
\text { et al. 2004; Hulsmeier et al. } \\
\text { 2007) }\end{array}$ \\
\hline Abl & $\mathbf{I}(\mathrm{Dm})$ & $\begin{array}{l}\text { Slit, EphrinA, and Netrin } \\
\text { pathway }\end{array}$ & $\begin{array}{l}\text { (Wills et al. 1999a; Bashaw et al. } \\
\text { 2000; Yu et al. 2001; Forsthoefel } \\
\text { et al. 2005) }\end{array}$ \\
\hline Fascin & $\mathbf{I}(\mathrm{Dm})$ & Trajectory maintenance & (De Arcangelis et al. 2004) \\
\hline \multicolumn{4}{|c|}{ F-actin Severing Proteins } \\
\hline Cofilin & I (MR, Dm), C, C-R & $\begin{array}{l}\text { Netrin, NGF, Semaphorin, } \\
\text { BMP, SLIT }\end{array}$ & $\begin{array}{l}\text { (Marsick et al.; Aizawa et al. 2001; } \\
\text { Piper et al. 2006) }\end{array}$ \\
\hline \multicolumn{4}{|c|}{ F-actin Depolymerizing Proteins } \\
\hline Mical & $\mathbf{I}(\mathrm{Dm})$ & Sema pathway & (Hung et al. 2010) \\
\hline \multicolumn{4}{|c|}{ Monomer Binding Proteins } \\
\hline CAP & $\mathbf{I}(\mathrm{Dm})$ & SLIT pathway & (Wills et al. 2002) \\
\hline Profilin & I (Dm) & ISNb & (Wills et al. 1999b) \\
\hline \multicolumn{4}{|c|}{ Arp $2 / 3+$ Activating Factors } \\
\hline WASP/WAVE & I (Dm, Ce) & Netrin, Semaphorin & (Zallen et al. 2002) \\
\hline Arp2/3 subunits & I (Dm, Ce) & Netrin, Semaphorin & $\begin{array}{l}\text { (Strasser et al. 2004; Shakir et al. } \\
\text { 2008; Norris et al. 2009) }\end{array}$ \\
\hline \multicolumn{4}{|c|}{ F-actin Motor Proteins } \\
\hline Myosin IIA & C-R & $\begin{array}{l}\text { Required for Sema3A/ RGMa } \\
\text { collapse }\end{array}$ & $\begin{array}{l}\text { (Kubo et al. 2008; Brown et al. } \\
\text { 2009) }\end{array}$ \\
\hline Myosin IIB & C-R & $\begin{array}{l}\text { Required for Sema3A } \\
\text { retraction }\end{array}$ & (Brown and Bridgman 2009) \\
\hline \multicolumn{4}{|c|}{ F-actin-Cytoskeletal-Linking Proteins } \\
\hline Short Stop/ACF7 & $\mathbf{I}(\mathrm{Dm})$ & Required for repulsion & $\begin{array}{l}\text { (Lee et al. 2007; Sanchez-Soriano } \\
\text { et al. 2009) }\end{array}$ \\
\hline MAP1B & & Netrin & (Del Rio et al. 2004) \\
\hline $\begin{array}{l}\text { POD1 } \\
\text { Guidance Assays }\end{array}$ & $\mathbf{I}(\mathrm{Dm})$ & ISN, SNa, ISNb neurons & (Rothenberg et al. 2003) \\
\hline
\end{tabular}

(S) Substrate-Stripe, (C) Collagen Gel, (C-R) collapse/retraction, (I) In vivo, (Ce) C. elegans, (Dm) Drosophila, (Dr) zebrafish, (Gg) chicken, (MR) mouse/rat, (XI) Xenopus, (P) pipet assay, (M) Micro-CALI. 
2000; Yu et al. 2002) and Lamellipodin (Lpd) (Krause et al. 2004); the significance of these interactions is discussed below.

Ena/VASP proteins promote assembly of long, sparsely branched actin filament networks. Ena/VASP increases filament length by interacting directly with free barbed ends and 1) binding profilin:G-actin complexes and directly transferring actin monomer from profilin to the barbed end, 2) enhancing the rate of actin polymerization, and 3) delaying termination of filament elongation by F-actin capping proteins (Bear et al. 2002; Barzik et al. 2005; Chereau and Dominguez 2006; Ferron et al. 2007; Breitsprecher et al. 2008; Pasic et al. 2008; Bear and Gertler 2009). In addition to the effects on filament elongation, Ena/VASP activity reduces Arp2/3 branching density in growing F-actin filament networks. Depending on the cellular context, the actin networks shaped by Ena/ VASP give rise to filopodia (when the long, unbranched filaments are bundled) or dynamic, protrusive lamellipodia.

Drosophila Enabled (Ena) was identified initially in a screen for dominant genetic suppressors of phenotypes arising in part from loss of the Abl tyrosine kinase homolog. Complete loss of Ena resulted in gross defects in the organization of axonal fiber tracts in the CNS (Gertler et al. 1990; Gertler et al. 1995). Subsequent work established that Ena is required to guide neurons in the intersegmental nerve $b$ (ISNb) to their proper targets, and that Ena function was required in axons for function, ruling out the possibility that the guidance defect arose as a secondary consequence of defects in other cell types (Wills et al. 1999b). Consistent with the previously noted antagonism between Ena and $\mathrm{Abl}$ activites, genetic interaction data indicated that Ena and Abl have opposing functions in ISNb guidance (Wills et al. 1999b). Though Ena is a substrate for the tyrosine kinase activity of Drosophila Abl (Gertler et al. 1995; Wills et al. 1999b), it is unclear what role Abl-mediated phosphorylation of Ena plays in this interaction since mutation of all the mapped Abl phosphorylation sites in Ena has only a modest effect on Ena function (Comer et al. 1998), and none of the sites phosphorylated in Ena are conserved in any of the vertebrate Ena/VASP proteins (Gertler et al. 1996).

Ena/VASP has important roles in guidance downstream of both attractive and repulsive cues. Mutations in C. elegans unc-34 (Yu et al. 2002; Gitai et al. 2003), Drosophila Ena (Wills et al. 2002), and deletion of Mena/VASP/EVL in mice (Lanier et al. 1999; Menzies et al. 2004) all cause midline axon crossing defects, in addition to other phenotypes. The phenotypic similarities and genetic interactions observed between Ena and Robo (or unc-34 and sax-3) mutants suggested roles for Ena/VASP downstream of the repulsive guidance receptor Robo (and the orthologous SAX-3 in C. elegans) receptors (Bashaw et al. 2000; Yu et al. 2002). The cytoplasmic tail of most Robo family receptors contains at least one EVH1-binding site, called "CC2" (Dickson and Gilestro 2006), that is conserved in most members of the Robo family, and that binds Ena/VASP proteins robustly (Bashaw et al. 2000; Yu et al. 2002). Deletion of CC2 in Drosophila reduces Robo function significantly, suggesting that direct interactions may be important for Ena/VASP to function as a Robo effector. It is clear, however, that in Drosophila and C. elegans, there must be other connections between Robo and the cytoskeleton beyond Ena/VASP since loss of the genes encoding the various Robo proteins lead to phenotypes that are more severe and penetrant than those caused by loss of Ena/VASP. Exactly how Ena/VASP proteins, which promote actin polymerization and filopodial/lamellipodial protrusion, enhance repulsive axon guidance downstream of Robo remains to be determined.

Ena/VASP also functions in response to netrin, a guidance factor that can elicit attractive or repulsive responses depending on receptor subunit composition and the status of second messenger signaling pathways (Moore et al. 2007). UNC-5, a receptor that mediates repulsion to netrin, induces dorsally directed axon outgrowth when expressed ectopically in classes of C. elegans neurons that normally extend along longitudinal or ventral trajectories. A screen for genes required for UNC-5-induced dorsal guidance phenotypes resulted in the isolation of a small number of genes including, among others, 
E.W. Dent et al.

unc-6 (netrin), unc-40 (DCC), unc-44 (Ankyrin, an F-actin binding protein), and unc-34 (Ena/ VASP) (Colavita and Culotti 1998). Therefore, it is likely that Ena/VASP functions in normal UNC-5-dependent repulsion to netrin.

In addition to their function downstream of UNC-5, experiments in both Drosophila and C. elegans indicate that Ena/VASP contributes to phenotypes arising from chimeric or constitutively active forms of the netrin receptor DCC (Gitai et al. 2003; Forsthoefel et al. 2005) (DCC orthologs are: Frazzled in Drosophila and UNC40 in C. elegans). Further analysis verified that Ena/VASP mediates part of the normal chemoattractive response to netrin during axon guidance. Understanding the nature of Ena/VASP mutant axon guidance phenotypes in all model systems is complicated by the dual roles of Ena/VASP in both attraction and repulsion in response to both netrin and Robo-mediated repulsion. Examination of unc-34 phenotypes in C. elegans lacking SLIT-Robo guidance provided unambiguous confirmation that Ena/ VASP is indeed required for netrin attraction (Gitai et al. 2003).

Mutational analysis of an activated form of UNC-40 revealed that UNC-34 functions downstream of a conserved cytoplasmic motif known as P1 (Gitai et al. 2003). The same study revealed that the $\mathrm{Rac}$ and ablim orthologs (mig-10 and unc-115, respectively) function downstream of the UNC-40 P2 motif and act in parallel to UNC-34. Subsequent genetic analysis suggested that UNC-115 function affects filopodia formation, perhaps in parallel to UNC-34 (Norris et al. 2009). While the role of the conserved P1 and P2 motifs in expressing the activated UNC-40 phenotype is clear, their role in normal axon guidance is less clear as the fra mutant phenotype in Drosophila can be rescued using fra transgenes that lack $\mathrm{P} 1$ and P2 (Garbe et al. 2007b). Whether UNC-34 interacts directly with UNC-40, or whether adaptor proteins connect them via a downstream signaling pathway, is presently unknown. Regardless of how Ena/VASP proteins are linked to UNC-40/DCC signaling, however, they are required to elicit filopodia formation and elongation after netrin stimulation in vivo (Chang et al. 2006) and in cultured cortical neurons (Lebrand et al. 2004).

One mechanism that may coordinate Ena/ VASP function in filopodia formation with netrin-mediated guidance responses involves PKA signaling (PKA; cAMP-dependent kinase). Second messenger signaling by cAMP and cGMP plays significant roles in axon guidance by modulating the intensity of responses to cues and perhaps by inducing conversion between attractive and repulsive responses to certain guidance cues (Bashaw and Klein 2010). Cultured neurons treated with netrin exhibit a robust increase in filopodia formation (Shekarabi and Kennedy 2002) that requires Ena/VASP, among other cytoskeletal regulatory proteins, and PKA activity (Lebrand et al. 2004); neurons treated with PKA activators elaborate filopodia (Chen et al. 2003; Argaw et al. 2008) in an Ena/VASP-dependent manner (Lebrand et al. 2004). At present, it is unknown whether PKA phosphorylation of Ena/VASP is essential for netrin-elicited filopodia induction.

While it seems likely that netrin elicits filopodia formation through a process that requires PKA and Ena/VASP in cultured neurons, other data preclude a simple netrin $>$ DCC $>$ cAMP $>$ PKA $>$ Ena/VASP pathway. Treatment with netrin does not increase global cAMP levels or PKA activation (Bouchard et al. 2004; Bouchard et al. 2008; Bashaw and Klein 2010), so it remains unclear how Ena/VASP phosphorylation levels rise upon netrin stimulation. Furthermore, PKA is not required for axon extension towards netrin in vivo, but enhances chemoattraction to netrin, at least in part, by increasing surface levels of DCC (Bouchard et al. 2004).

The role of both Ena/VASP and filopodia formation in axon guidance has been questioned based on the ability of retinal axons to navigate properly while expressing an Ena/ VASP function-blocking construct (Dwivedy et al. 2007) that depletes and sequesters Ena/ VASP (Bear et al. 2000). This construct was transfected into the retina of developing Xenopus, and the axons expressing the construct were monitored for filopodia formation, axon navigation, and terminal arborization (Dwivedy 
et al. 2007). Despite a significant reduction in filopodia in the axons that expressed the inhibitory construct, these axons made their way to their target region but exhibited defects in terminal branching and final target selection. This result has been interpreted as evidence that filopodia and Ena/VASP are not required for accurate axon guidance (Dwivedy et al. 2007; Lowery and Van Vactor 2009). If true, this conclusion would be surprising given the extensive genetic evidence in Drosophila, C. elegans, and mice demonstrating roles for Ena/VASP in multiple guidance pathways. Another interpretation of these data is that a major guidance decision made by retinal axons is whether and where to branch in the tectum. It is important to note that the transfection approach used is limited in that it is not possible to be certain when the inhibitory construct was expressed at levels sufficient to block Ena/VASP. Furthermore, only a small subset of neurons in the retina were transfected, therefore it is likely that pioneering axons were not affected by the inhibitory construct. Compensation for Ena/VASP could occur during outgrowth to the target via fasciculation; however, branch formation in the tectum occurs by interstitial axon branching after the primary growth cone has extended beyond the target (McLaughlin et al. 2003). Thus, topographically specific interstitial branching is a major form of guidance in the tectum, and it is particularly sensitive to Ena/VASP disruption (Dwivedy et al. 2007). This hypothesis is consistent with the ability of Ena/VASP to affect branching in murine hippocampal (Lebrand et al. 2004) and cortical (Dent and Gertler, unpubl.) neurons, two neuronal types that branch primarily by interstitial branching (Halloran and Kalil 1994).

\section{MRL Proteins}

Ena/VASP are also linked to both netrin and Slit-dependent guidance by their direct interaction with MRL proteins: MIG-10 in C. elegans, and Lamellipodin (Lpd) and RIAM in vertebrates (Krause et al. 2004; Chang et al. 2006; Quinn et al. 2006; Quinn et al. 2008; Michael et al. 2010; Smith et al. 2010). In addition to acting as downstream signaling components of netrin and Slit guidance pathways, MIG10 plays a role in the initial establishment of asymmetry in the HSN neuron. Prior to HSN axon formation, MIG-10 accumulates on the side of the cell oriented toward a netrin source, the earliest known molecule to exhibit such Netrin-dependent asymmetric localization. MRL proteins are linked to second messenger signaling by tyrosine kinases and by binding to phosphinositides such as PI $(3,4)$ P2 and to Ras superfamily proteins. Consistent with a role for PI $(3,4) \mathrm{P} 2$ in spatiotemporal regulation of MRL localization, mutations in age-1, a PI3K, impair netrin-dependent localization of MIG-10, most likely because PI3K activity is required to produce $\mathrm{PI}(3,4) \mathrm{P} 2$ among other phosphoinositides. MRL proteins promote actin polymerization, membrane protrusion, and can regulate activation of adhesion receptors. Genetic and cell biological evidence indicate that while Ena/VASP is required for full MRL function, other actin regulators act downstream of MRL signaling. Clearly, implementation of fluorescent biosensors and development of phospho-specific antibodies that can be used for immunolocalization will be required to examine spatiotemporal signaling to the cytoskeleton downstream of netrin and other guidance cues.

\section{DAAM1}

Recent work implicates another barbed-end binding protein, disheveled-associated activator of morphogenesis (DAAM), as a regulator of filopodia formation and axonal morphogenesis in Drosophila (Matusek et al. 2008). DAAM is a member of the formin protein superfamily that nucleates linear actin filaments, regulates filament growth rate through processive elongation (continuous attachment to the growing end), and can block filament termination by barbed-end capping proteins. Most formin proteins contain three conserved domains: the GTPase binding domain (GBD), Formin homology 1 (FH1) domain, and Formin homology 2 (FH2) domain (Higgs 2005). Formins are autoinhibited by head-to-tail intramolecular 
E.W. Dent et al.

interactions that are typically relieved by binding to Rho GTPases, thereby allowing the FH1 and $\mathrm{FH} 2$ to bind effectors and drive actin polymerization (Goode and Eck 2007). The FH1 domain binds to profilin, while the $\mathrm{FH} 2$ domain contains the core nucleating activity. Unlike other formins, DAAM1 is activated by binding to Dvl, a component of noncanonical Wnt signaling pathways (Liu et al. 2008), raising the interesting possibility that this molecule could be involved in Wnt-mediated guidance.

The Drosophila DAAM1 ortholog "DAAM" is expressed highly in the nervous system (Matusek et al. 2008). Loss-of-function analysis and targeted expression of activated constructs revealed that DAAM plays significant roles in filopodia formation on axonal growth cones: Loss of DAAM reduces the frequency of filopodia formation in primary cultures from mutants, while expression of activated DAAM increases filopodia formation. Most eukaryotes possess multiple formin genes (Higgs 2005; Higgs and Peterson 2005), and the cellular roles of these proteins have recently been explored. Mutant embryos lacking functional DAAM exhibit a range of CNS phenotypes that are observed in about a third of the embryos lacking both the maternally and zygotically produced protein. The DAAM mutants show occasional gaps in longitudinal connectives and more severely affected embryos show malformed commissures, misrouted axons, or failures in commissure separation (Matusek et al. 2008). Genetic interaction studies indicate that reduced levels of DAAM exacerbate phenotypes caused by loss of Rac and vice versa, showing that these two proteins function in interdependent, or perhaps parallel, pathways important for axon outgrowth and guidance. Similarly, reduction in Ena or profilin levels exacerbated the DAAM loss-of-function phenotype. Expression of a constitutively active form of DAAM induced a variety of defects, including a partial collapse of the longitudinal tracts that could be ameliorated significantly by reducing Ena levels. Therefore, it appears that there is likely significant interplay between DAAM and Ena function during axon outgrowth and guidance.
Coimmunoprecipitation of various formins in different systems revealed that there are small pools of Ena/VASP in complex with formins (Grosse et al. 2003; Schirenbeck et al. 2006; Homem and Peifer 2009). The distribution of DAAM and Ena overlaps partially in growth cone filopodia (Matusek et al. 2008), so these two molecules may interact as well. While various models have been proposed to explain the function of a formin:Ena/VASP complex, none have been tested rigorously. Regardless, it seems likely that complexes between multiple molecules that can each independently drive filopodia formation may exist. This offers the growth cone exquisite flexibility to respond rapidly to distinct guidance cues that trigger activation of a subset of such filopodia-promoting proteins. In the future, it will be interesting to see if DAAM acts in the same guidance pathways as Ena. In this respect, it is curious that mutations in genes encoding DAAM or other formin superfamily proteins have not been recovered in genetic screens conducted in Drosophila and C. elegans for axon guidance defects or for modifiers of guidance pathways, while mutations in Ena/VASP genes have been identified repeatedly. Given the large number of formin family members (Higgs 2005; Higgs and Peterson 2005), it is likely that future studies will reveal that other formins are involved in growth cone morphology and guidance. It will be interesting to further define how formin family proteins and Ena/VASP proteins cooperate in filopodia formation and axon guidance.

\section{Capping Proteins}

Not all barbed-end-binding proteins facilitate actin polymerization. Capping proteins bind to the barbed ends of actin filaments and block access of monomers to the barbed end, thus halting polymerization and reducing the length of F-actin (Xu et al. 1999). Antagonism between filament elongation/protection factors and capping proteins contributes to filopodial dynamics. In fact, while filopodial formation has been the subject of great interest, relatively little is understood about the mechanisms that govern filopodial withdrawal, including 
The Growth Cone Cytoskeleton in Axon Outgrowth and Guidance

determining which of the many filament capping proteins play predominant roles in negatively regulating filopodial dynamics in growth cones. Hippocampal neurons from mice lacking gelsolin, a protein that severs actin filaments in a $\mathrm{Ca}^{2+}$-dependent manner and caps the free barbed ends of the severed filaments (Sun et al. 1999), have increased numbers of filopodia that arise as a consequence of reduced retraction (Lu et al. 1997). A role for gelsolin in axon guidance has not been reported. Similarly, deletion of the multifunctional capping protein EPS8, which interacts with a number of signaling proteins involved in Rac and Ras signaling, as well as having actin filament capping activity, results in increased filopodia number after treatment of hippocampal neurons with BDNF (Menna et al. 2009). EPS8 knockout mice do not show any obvious axon guidance defects; however, the expression of two EPS8-related molecules during development may mask a possible requirement for EPS8.

The most widely studied capping protein, heterodimeric capping protein (CP), does indeed mediate growth cone morphology, axon elongation, and possibly axon guidance. In Drosophila, reduction in filament elongation/ anti-capping activity of Ena ameliorates $a b l$ phenotypes, including defects in axon guidance (Gertler et al. 1990; Gertler et al. 1995; Wills et al. 1999b; Drees and Gertler 2008). Based on this finding, Grevengoed and colleagues examined the effects of reducing CP levels in $a b l$ mutants and found that such animals exhibit more severe phenotypes than those observed in $a b l$ mutants alone with respect to morphology of the nervous system (the opposite of the effect observed upon reduction of Ena levels) (Grevengoed et al. 2003). Therefore, CP may play a role in axon guidance through its wellcharacterized ability to cap growing actin filaments. Careful analysis of $c p$ loss-of-function mutants is required to assess the role of $\mathrm{CP}$ in axon outgrowth and guidance.

Unexpectedly, CP also appears to have a role in controlling growth cone morphology and axon elongation independent of its capping activity. Loss of a CP subunit, CapzB2, resulted in aberrant growth cone morphology and neurite outgrowth, and also mis-localized microtubules that extended into the peripheral domain of growth cones. Surprisingly, this phenotype is not a result of reduced capping, but instead arises due to loss of a newly identified interaction between CapzB2 and $\beta$ III tubulin. Mutants that maintained capping activity but lacked the ability to bind $\beta$ III tubulin could not rescue the phenotype, while capping deficient mutants that bound $\beta$ III tubulin rescued (Davis et al. 2009). This study supports the idea that proper localization of microtubules in the central region of the growth cone is necessary for normal growth cone morphology and translocation. It will be challenging to determine the relative contributions of tubulin binding and filament capping by $\mathrm{CP}$ in axon guidance. The control of filament capping during guidance, and its functional significance to navigation, remain outstanding questions in the field.

\section{F-actin Binding Proteins}

\section{ERM Proteins}

Proteins that bind to the sides of actin filaments affect the architecture of cellular F-actin networks and can tether the cytoskeleton to different locations or functional partners. Ezrin, radixin, and moesin comprise the ERM family of highly homologous, multifunctional F-actin binding proteins. ERMs contain an N-terminal membrane binding domain linked by an $\alpha$-helical region to a $\mathrm{C}$-terminal actin-binding domain, allowing them to tether the actin cytoskeleton to the plasma membrane through interactions with PIP2 and L1CAM (Algrain et al. 1993; Turunen et al. 1994; Chishti et al. 1998). They are expressed in the developing nervous system and are concentrated specifically in growth cones (Goslin et al. 1989; GonzalezAgosti and Solomon 1996; Paglini et al. 1998; Takahashi et al. 1999; Dickson et al. 2002; Mintz et al. 2008), making them well positioned to coordinate growth cone responses to guidance cues. Suppression of radixin and moesin results in reduced grow cone area, disorganized Factin, and lamellipodial veil retraction (Paglini et al. 1998); while these growth cones display 
E.W. Dent et al.

increased filopodial activity, their rate of advance is significantly impaired and axonal maturation is aberrant (Paglini et al. 1998). Since the L1CAM adhesion molecule has been reported to form a complex with neuropilin1, the Sema3A obligate co-receptor, a role for ERMs in the response to Sema3A was investigated (Mintz et al. 2008). Activated ERMs (as detected with a phospho-specific antibody that recognizes a phosphorylation site that induces ERMs to change conformation into an active state) were localized asymmetrically within growth cones and are rapidly and transiently inactivated by Sema3A. Expression of F-actin binding defective ERM mutants induces defects in axonal orientation in a slice overlay assay and impairs Sema3A-induced growth cone collapse (Mintz et al. 2008). The multifunctional protein and phosphoinositide binding FERM domain (Tepass 2009) within ERMs regulates neuropilin1 endocytosis when ERMs are activated, while the C-terminal ERM domain binds and caps F-actin, suggesting that ERMs coordinate membrane and actin dynamics (Mintz et al. 2008). The potential role of ERMs in Sema3A-elicited endocytosis is especially intriguing in light of evidence suggesting that asymmetric endocytosis is required for Sema3a-mediated repulsive guidance (Tojima et al. 2010). Other studies have implicated ERMs in the control of adhesion and axon branching in addition to Sema3A collapse (Schlatter et al. 2008). Consistent with the proposed role for ERMs in axon outgrowth and guidance, RNAi depletion of the sole ERM ortholog in C. elegans causes mild defects in axon outgrowth and morphology. It will be interesting to see if loss-of-function analysis of the ERM proteins in other systems yields results similar to those observed by the expression of mutant proteins.

\section{UNC-115/Ablim}

The C. elegans F-actin binding protein UNC115 is similar to the human protein ablim/ limatin (Struckhoff and Lundquist 2003); it has a villin headpiece domain, found in several other actin binding proteins, and three LIM domains. UNC-115 function is likely involved as an effector of multiple guidance signaling pathways (Lundquist et al. 1998) and is known to function downstream of activated unc-40/ DCC (Gitai et al. 2003). Genetic interaction experiments place unc-115 downstream of the GEF unc-73/TRIO. Further experiments place UNC-115 downstream of two Rac proteins, CED-10, a component of the UNC-40/DCC pathway, and RAC-2/3 (Struckhoff and Lundquist 2003). Exactly how Rac signals to UNC115 remains to be determined.

Analysis of animals overexpressing unc-115 and of unc-115 loss-of-function mutants revealed significant roles for UNC-115 in modulating filopodia formation and growth cone size (Yang and Lundquist 2005; Norris et al. 2009). Mutations in the Drosophila ablim/ Unc-115 homolog, Dunc-115, revealed defects in retinal axon projection to the lamina (Garcia et al. 2007). Mammals have three highly related UNC-115 paralogs. Deletion of a single splice isoform of ablim1 revealed no apparent defects in neuronal structures that express this ablim isoform most robustly, including photoreceptors, inner retinal neurons, and the retinofugal projections, perhaps because the other ablim 1 splice isoforms were still expressed in the knockout animal (Lu et al. 2003). Ablim2 and ablim3 are also expressed in the nervous system and may compensate for loss of ablim1 (Barrientos et al. 2007). Consistent with this idea, when a putative dominant-negative form of ablim lacking the F-actin binding region was introduced into the developing chick retina, retinal axons exhibited strong pathfinding and fasciculation defects (Erkman et al. 2000).

How does UNC-115 function to link guidance to F-actin and the regulation of filopodia and lamellipodia? The molecular mechanisms by which UNC-115 functions beyond binding to F-actin and localizing to bundled F-actin in cells are not fully understood. High levels of UNC-115 expression in cultured cells can induce aberrant F-actin bundles (Yang and Lundquist 2005), consistent with a potential bundling activity of UNC-115. UNC-115 may also recruit additional proteins to the cytoskeleton. Interestingly, ablim2 and ablim3 (and most likely ablim1) bind directly to the evolutionarily 
conserved F-actin binding protein "STARS." Like the ablims, STARS localizes to F-actin bundles and F-actin-rich regions in cultured cells (Arai et al. 2002). Interestingly, when overexpressed STARS stimulates Rho GTPase-dependent Factin assembly leads to activation of the SRF transcription factor (Arai et al. 2002).

SRF-dependent transcription is required for proper neuronal morphology and axon guidance (Knoll et al. 2006; Stern et al. 2009). Many SRF target genes are cytoskeletal proteins or signaling proteins that regulate cytoskeletal dynamics and, interestingly, SRF activity itself is regulated by the status of the actin cytoskeleton (Posern and Treisman 2006; Knoll and Nordheim 2009). Monomeric actin binds to MAL, an SRF co-factor, and inhibits the ability of MAL to activate SRF. Under conditions where the F-actin:G-actin levels are high, MAL can bind SRF, leading to transcription. Conversely, when the amount of F-actin decreases and G-actin levels rise, MAL is inhibited and thereby blocks SRF activity. The ablims enhance STARS-driven SRF activation, and RNAi depletion of the ablims impairs STARS activation of SRF (Barrientos et al. 2007). This leads to an interesting question: Could altered F-actin:G-actin ratios arising during guidance responses mediated by UNC-115/ablim or other cytoskeletal regulators in the growth cone influence gene expression during guidance? MAL-dependent SRF-transcription can be modulated by synaptic activity, indicating that F-actin:G-actin ratios can affect SRF by long-range signaling. NGF-dependent axon growth, branching, and target innervation requires that SRF and NGF-stimulated DRG neurons exhibit MAL-dependent SRF activation (Knoll and Nordheim 2009). Therefore, the MAL-SRF pathway may be capable of responding dynamically to outgrowth/guidance factors, though this intriguing hypothesis awaits formal proof.

Consistent with a role in signaling for F-actin:G-actin dynamics during axon guidance, conditional deletion of SRF in the hippocampus results in guidance defects in the mossy fiber tracts (Knoll and Nordheim 2009). SRFdeficient hippocampal neurons have abnormal growth cone morphology, exhibit few or no filopodia, do not collapse in response to ephrin A, and develop abnormal thick looped F-actin and MT bundles in the growth cone periphery. Of course, SRF deletion and inhibition experiments could lead to chronic changes in gene expression that in turn might affect guidance. Whether the ablim-STARS pathway, or other guidance molecules that can shift the F-actin:G-actin ratio, do actually connect the dynamic changes in the status of the growth cone cytoskeleton during guidance to alteration of gene expression remains to be determined.

\section{Fascin}

Fascin, a potent $\mathrm{F}$-actin bundling protein found in filopodia, is highly expressed in the developing nervous system of mouse (De Arcangelis et al. 2004). Fascin cross-links and stabilizes actin filaments, giving rise to parallel/unipolar F-actin bundles (Sasaki et al. 1996; Aratyn et al. 2007), and it is involved in filopodia formation in multiple cell types (Vignjevic et al. 2006). In the large growth cones of the helisoma snail, inhibition of fascin with TPA, a PKC agonist, resulted in a marked loss of actin bundles within growth cones, suggesting that fascin is crucial for the maintenance of filopodia and normal growth cone morphology (Cohan et al. 2001). Loss of fascin function in Drosophila results in impaired neurite morphology and a failure in proper trajectory maintenance (De Arcangelis et al. 2004), suggesting that fascin may be involved in motility or guidance. Consistent with this idea, semaphorin-induced growth cone collapse is associated with an increase in fascin localization, which the authors suggest increases the F-actin bundles required for myosin-based contraction/retraction (Brown and Bridgman 2009).

Loss-of-function analysis in Drosophila and mice, however, has yet to reveal a significant role for fascin in axon guidance. Gene targeted fascin1 mutant mice revealed that loss of fascin 1 had only subtle effects on nervous system development; the only potential guidancedependent phenotype involved a failure of the 
E.W. Dent et al.

posterior portion of the anterior commissure to form (Yamakita et al. 2009). Dorsal root ganglia cultured from the fascin1 knockouts exhibit fewer and shorter filopodia, though they are able to extend axons normally (Yamakita et al. 2009). The subtle phenotype observed in fascin 1 mutants is unlikely due to overlapping expression with fascin paralogs, as neither of the two other fascin genes in mice are expressed in the developing nervous system (outside of the retina). Other actin bundling proteins might substitute for fascin, or alternatively, homeostatic regulatory mechanisms might partially compensate for fascin and allow for normal nervous system development. It seems likely that genetic interaction screens in Drosophila or C. elegans may be necessary to identify conditions that sensitize animals to a loss of fascin function during nervous system development.

\section{$\mathrm{Abl}$}

The Ableson (Abl) nonreceptor tyrosine kinase mediates transduction of signals from growthfactor and adhesion receptors and regulates a diverse array of signaling pathways, including many involved in cytoskeletal regulation (for a comprehensive Abl-targets and ligands review, see Bradley and Koleske 2009). Abl and Arg (an Abl-related gene) are the only known nonreceptor tyrosine kinases that bind the actin cytoskeleton directly; in addition, Arg (but not Abl) can bind MTs. Drosophila Abl contains the actin binding, but not MT, interacting motifs; therefore, we focus on Abl as an actin-binding kinase. Direct interactions with actin support F-actin bundling by Abl and Arg. Cytoskeletal interactions may also help concentrate $\mathrm{Abl}$ family proteins in close proximity to key targets that can regulate the dynamics of membrane protrusion. Abl proteins can also bind and/or phosphorylate other cytoskeletal regulatory proteins such as WAVE family proteins, Cortactin, and Ena/VASP. Abl can also regulate cytoskeletal dynamics by modulating the activity of GEFs and GAPs for Rho family proteins. Abl is therefore of great interest with respect to its ability to interact directly with F-actin and for the many genetic and biochemical interactions that link it to cytoskeletal regulatory proteins during axon guidance.

The evidence that implicates Abl in axon guidance in vivo stems from work in Drosophila, where functional $\mathrm{Abl}$ is required in concert with various interacting genes to form axonal connections in the embryonic nervous system (Gertler et al. 1989); Elkins et al. 1990; Wills et al. 1999a; Bashaw et al. 2000; Liebl et al. 2000; Wills et al. 2002; Liebl et al. 2003; Lee et al. 2004; Forsthoefel et al. 2005; Lowery et al. 2010). The ladder-like embryonic CNS axon scaffold of Drosophila is severely disrupted if both maternal and zygotic contributions of Abl protein are eliminated (Grevengoed et al. 2001). While the CNS is fairly normal in zygotic $A b l$ mutants, widespread disruption in CNS axonal connections is observed in $\mathrm{Abl}$ mutant embryos also harboring a mutation in the adhesion molecule fasciclin I (Elkins et al. 1990). In addition, CNS defects are observed in $\mathrm{Abl} \mathrm{mu-}$ tant embryos that have reduced levels of the adhesion receptor Neurotactin (Nrt) (Liebl et al. 2003), and also in Abl mutants that lack functional Armadillo, a Beta-catenin homolog that is a component of the N-Cadherin cell:cell adhesion machinery (Loureiro and Peifer 1998). These interactions suggest that one aspect of Abl function in the formation of the embryonic CNS involves modulation of cell:cell interactions. Beyond CNS midline crossing, Abl also regulates guidance of the ISNb motor axons. In $\mathrm{Abl}$ mutants, ISNb motor neurons stop short and fail to reach their targets, while overexpression results in these motor axons proceeding past their targets (Wills et al. 1999a). Abl function in ISNb guidance serves to antagonize the functions of Ena and the receptor tyrosine phosphatase DLAR in the establishment of these axon trajectories.

The role of Abl in regulating midline crossing has been investigated in several studies. Abl appears to act in multiple repulsive and attractive midline guidance systems. Abl binds, and can phosphorylate, the Robo receptor (Bashaw et al. 2000), potentially activating Robo and preventing axons from crossing the midline. Consistent with this model, a Robo-like phenotype is 
caused by overexpression of $\mathrm{Abl}$ in the nerve cord (Bashaw et al. 2000). Other genetic interaction analyses indicate that Abl collaborates with different sets of interacting molecules that either enhance, or dampen, midline crossing (Wills et al. 2002). Consistent with this idea, either too much or too little Abl activity causes axons to cross the midline inappropriately (Hsouna et al. 2003). Therefore, a precise balance between Abl function and Abl interaction partners is essential for proper midline guidance.

Genetic evidence in Drosophila also implicates $\mathrm{Abl}$ in netrin-mediated guidance. $\mathrm{Abl}$ mutations exacerbate Fra(DCC) and netrin CNS mutant phenotypes; Fra/Abl double mutants show a marked reduction in commissural axons (Forsthoefel et al. 2005). Consistent with an in vivo role for $\mathrm{Abl}$ as an effector of Fra signaling, $A b l$ heterozygosity reduces the number of axons that inappropriately cross the midline in embryos expressing a chimeric Robo-Fra receptor. Fra can be coimmunoprecipitated with $\mathrm{Abl}$ and may be an Abl substrate (Forsthoefel et al. 2005). Another guidance receptor, Dscam, which acts in both netrin-dependent and netrin-independent guidance, exhibits a potent synthetic interaction with $\mathrm{Abl}$ mutations that give rise to severe midline crossing defects (Andrews et al. 2008).

$\mathrm{Abl}$ has been linked functionally to cytoskeletal regulation by genetic data, indicating that accurate axon guidance requires a precise balance between Abl signaling pathways and cytoskeletal-binding proteins that regulate actin dynamics. As noted previously, reduction in Ena levels can suppress many Abl-dependent phenotypes (Gertler et al. 1990; Gertler et al. 1995; Wills et al. 1999a). Other cytoskeletal proteins have been implicated in Abl-mediated guidance. These include: trio (a rac GEF that functions with $\mathrm{Abl}$ in netrin responses [Liebl et al. 2000; Forsthoefel et al. 2005]); Abi (an adaptor protein that functions antagonistically with $\mathrm{Abl}$ and can also bind various actin regulatory and signaling proteins [Lin et al. 2009]); and cap (an actin monomer binding protein [Wills et al. 2002]). Interestingly, Abl is also connected to MT dynamics through potent interactions with two proteins, orbit/CLASP and Msps (mini spindles), both of which are +TIPs protein (Lee et al. 2004; Lowery et al. 2010). Therefore, Abl appears poised to coordinate actin and MT dynamics during guidance responses.

In vertebrates, the role of $\mathrm{Abl}$ and Arg in axon guidance is less clear than it is for Drosophila Abl. Abl can interact with the Ephrin-A receptors, EphB2 and EphA4 (Yu et al. 2001), and is necessary for proper ephrinA-induced repulsion in cultured retinal axons (Harbott and Nobes 2005). Surprisingly, despite a wealth of evidence implicating Abl in multiple guidance pathways in Drosophila, clear roles for Abl and the related Arg kinases have yet to be demonstrated in vivo in vertebrates. Mice in which both Abl and Arg were deleted specifically in the nervous system exhibit no obvious axon guidance defects (Moresco et al. 2005; Bradley and Koleske 2009). Furthermore, axon guidance phenotypes have not been reported for mutations in the C. elegans Abl ortholog.

There is no simple explanation for why Drosophila Abl is involved in so many guidance processes while similar roles for $\mathrm{Abl}$ in other systems have not been evident. One possible explanation involves the relatively poorly conserved carboxy terminus of Abl. While the activity of the highly conserved mammalian Abl kinase domain can substitute for fly $\mathrm{Abl}$ during this process (Henkemeyer et al. 1990; Wills et al. 1999a), the vertebrate c-terminus is not functional in the fly. The large c-terminal domain of Abl family proteins is unique among receptor tyrosine kinases and contains, among other features, the actin-binding sites found in all Abl proteins. Transgenic rescue experiments revealed that while the vertebrate amino terminal portion of $\mathrm{Abl}$ (including the $\mathrm{SH} 3, \mathrm{SH} 2$, and tyrosine kinase domains) can functionally substitute for the Drosophila Abl protein, the c-terminus cannot (Henkemeyer et al. 1990). Interestingly, Drosophila Abl has two EVH-1 (Ena/VASP Homology) binding motifs in its carboxy terminus that are not conserved in Abl family proteins found in other species; it would be interesting to determine whether direct binding of Ena and $\mathrm{Abl}$ at these sites plays 
E.W. Dent et al.

a significant role in their genetic interactions in Drosophila.

\section{UNC-44}

Mutations in $u n c-44$ were identified in a screen for suppressors of the guidance defects induced by ectopic expression of unc-5 (Colavita and Culotti 1998). The unc-44 gene encodes an ankyrin-related protein (Otsuka et al. 1995) that is likely a component of the cortical cytoskeleton and contributes to the ankyrin-spectrin meshwork underlying the plasma membrane. Ankyrin is composed of three domains: 1) a membrane protein-binding domain containing 23 approximately 33 -amino-acid repeats (ankyrin repeats); 2) a spectrin-binding domain; and 3) a regulatory domain. unc-44 mutants in $C$. elegans exhibit aberrant axon guidance and fasciculation with inappropriate partners (Hedgecock et al. 1985; Zallen et al. 1999). While UNC-44 was among the first cytoskeletal proteins implicated in axon guidance, relatively little is known about how it participates in axonal guidance.

\section{Spectrin}

Spectrins form a multiunit integral structural element that links molecules in the cell membrane to the F-actin cytoskeleton to form the submembranous cortical spectrin network. The Spectrin family of F-actin binding proteins is expressed ubiquitously during development and organizes the protein network underlying the plasma membrane. Spectrins are comprised of $\alpha$ - and $\beta$-subunits. The $\alpha$-Spectrin subunit contains an SH3 domain, allowing it to connect the actin cytoskeleton to numerous other proteins (Nedrelow et al. 2003; Bialkowska et al. 2005), while $\beta$-Spectrin contains a $\mathrm{PH}$ domain, allowing direct binding to lipids in the membrane (Williams et al. 2004) and an Ankyrin-binding domain. Drosophila harboring mutations in the $\beta$-Spectrin gene exhibit axon guidance defects that include inappropriate midline crossing, while $\alpha$-Spectrin does not seem to be required for axon guidance (Garbe et al. 2007a; Hulsmeier et al. 2007). Both the Ankyrin-binding and $\mathrm{PH}$ domains are dispensable for $\beta$-Spectrin function in guidance. Genetic interactions implicate $\beta$-Spectrin in SLIT/ROBO-mediated midline repulsion as well (Garbe et al. 2007a).

\section{GAP-43}

GAP-43, an abundant F-actin binding protein that localizes to the membrane when it is palmitoylated, modulates the stabilization of actin filaments in a phospho-dependent fashion (He et al. 1997). GAP-43 knockout mice exhibit defects in the formation and guidance of the RGC axons, though different groups have reported varied phenotypes including "axon stalling" that is later corrected (Strittmatter et al. 1995), and enlargement of the optic chiasm subsequent to passage of the RGC axons (Kruger et al. 1998). Interestingly, GAP-43-deficient animals exhibit major defects in forebrain commissures, including the corpus callosum, anterior commissure, and hippocampal commissure (Shen et al. 2002). Thalamocortical targeting is also disrupted, resulting in aberrant topographical maps in cortex (Maier et al. 1999). However, GAP-43-deficient neurons still collapse in response to the midline repellent Slit-2 (Shen et al. 2002). This may be due to compensation by other family members such as MARCKS and CAP-23. Surprisingly, given that a GAP-43 deficiency results in decreased growth cone size and F-actin concentration in the growth cone (Aigner et al. 1995; Shen et al. 2002), GAP-43 function in other guidance cue pathways is presently lacking.

\section{Myosin II}

Myosin II is a motor protein that causes antiparallel filaments to contract, driving actin retrograde flow in growth cones (Lin et al. 1996). Myosin II is likely to play a major role in force production necessary for growth cone motility as well as aid in actin depolymerization by disruption of F-actin networks (Medeiros et al. 2006). Both roles are likely important for axon guidance. Myosin-II-based retrograde flow also affects microtubule dynamics and 
restricts the localization of the majority of microtubules to within the central domain of the growth cone (Burnette et al. 2008; Schaefer et al. 2008). To achieve directional motility, however, myosin II activity is likely regulated spatially by signaling from guidance cues. In Drosophila CNS neurons, expression of a constitutively active Myosin Light Chain Kinase (MLCK) causes incorrect midline crossing (Kim et al. 2002), confirming the importance of proper regulation of myosin II activity during axon guidance. Expression of active MLCK in conjunction with Slit or Robo mutants induced further defects in axon guidance, while activated MLCK expression decreased aberrant guidance in the context of Comm mutants. Similarly, the effects of active MLCK expression were exacerbated by increased Frazzled levels and suppressed by loss of Frazzled function (Kim et al. 2002). Therefore, attractive and repulsive guidance cues utilize myosin II activity. Signaling from Rho family proteins can regulate myosin II, and there is evidence that Rho family proteins link myosin II regulation to guidance receptors (Fritz and VanBerkum 2002; Gallo 2006; Loudon et al. 2006; Murray et al. 2010).

There are three distinct isoforms of nonmuscle myosin II (A, B, and C), and these have overlapping and distinct functions in various aspects of motility and adhesion (Vicente-Manzanares et al. 2009). A high-resolution study investigated the role of myosin II in repulsion (Brown et al. 2009). Application of the repellent Sema3A to mouse DRG neurons caused a redistribution of myosin IIB within the growth cone that coincided with a partial depolymerization of the F-actin meshwork but left large F-actin bundles intact. These bundles were proposed to act as the substrate for myosin-II-based contraction, driving growth cone collapse (Brown et al. 2009). Myosin IIA normally redistributes to the neurite neck during retraction. Myosin IIA overexpression blocks collapse and retraction of mouse DRGs (Brown et al. 2009), leading the authors to conclude that myosin IIA stabilizes the actin cytoskeleton to prevent retraction. In contrast, genetic deletion of myosin IIB or global inhibition of myosin II activity by blebbistatin treatment blocked retraction (Brown et al. 2009). During Sema3A treatment, Myosin IIB redistributes from a broad pattern over the entire growth cone to the rear of the growth cone and neck of the connecting neurite. To put these findings together, a model has been proposed in which Sema3A treatment leads to myosin IIA removal from the growth cone, reducing the stability of the actin network and inducing collapse. Subsequently, myosin IIB is thought to associate with the remaining actin bundles at the growth cone neck region to drive retraction (Brown et al. 2009).

\section{F-actin Severing Proteins}

\section{Cofilin}

Turnover and depolymerization of the actin cytoskeleton is an integral step in growth cone collapse and retraction, often triggering chemorepuslive turning. It is, however, important to bear in mind that efficient turnover and recycling of the actin cytoskeleton is essential for efficient locomotion (Sarmiere and Bamburg 2004). The most well-studied actin severing proteins are $\mathrm{ADF} /$ cofilin and gelsolin. Since cofilin is the predominant protein of this family in neurons, we refer to them collectively as "cofilin." Cofilin binds both monomeric and F-actin, but it prefers ADP-bound forms of actin (Maciver et al. 1998). When bound to F-actin, cofilin alters the twisting conformation of actin filaments, leading to filament severing (McGough et al. 1997). Cofilin also increases the rate constant of dissociation of monomers from the pointed end of actin filaments, leading to their depolymerization (Carlier et al. 1997). These activities promote filament assembly as cofilin reveals new polymerization-competent barbed ends, and increases the available pool of actin monomers (Chan et al. 2000; Ichetovkin et al. 2002; Ghosh et al. 2004). Cofilin activity is negatively regulated through phosphorylation by LIM kinases, whereas dephosphorylation by the slingshot phosphatase activates cofilin. Cofilin can also be regulated by binding to the phosphoinositide $\mathrm{PI}(4,5) \mathrm{P} 2$, 
E.W. Dent et al.

which sequesters the protein to the plasma membrane (Mouneimne et al. 2004).

Cofilin localizes to the growth cone and has been implicated in various axon guidance pathways (Aizawa et al. 2001; Piper et al. 2006; Marsick et al. 2010). A recent study utilizing both DRG and temporal retinal neurons from chick supports a role for cofilin in chemoattraction toward NGF and netrin-1, respectively. Following treatment with NGF or netrin-1, the inactive, phosphorylated, form of cofilin was decreased, indicating that cofilin is activated downstream of these attractive guidance cues (Marsick et al. 2010). Strikingly, asymmetric application of NGF or netrin-1 gradients induced increased levels of F-actin and free filament barbed ends oriented toward the gradient. The NGF and netrin gradients also induced formation of membrane protrusions directed toward the pipet. Using a system to deliver active cofilin directly into growth cones across the plasma membrane, the authors demonstrated that asymmetric cofilin activity could elicit directed actin assembly and protrusion, similar to what is observed following application of NGF or netrin (Marsick et al. 2010). Global activation of cofilin within the growth cone dampened actin assembly and growth cone turning toward guidance cues. These data suggest that asymmetric cofilin activity within a growth cone, induced by netrin-1 or NGF, can elicit attractive turning (Marsick et al. 2010). It is likely that asymmetric stimulation with a guidance cue induces cofilin activation adjacent to the plasma membrane. The active cofilin can then cleave capped actin filaments to liberate free barbed ends for polymerization; this is similar in principle to the role cofilin plays in chemotactic responses in carcinoma cells (Wang et al. 2007).

What about cofilin function during repulsion and growth cone collapse? Intuitively, it would be logical to enlist cofilin activity to depolymerize the actin cytoskeleton during repulsion and growth cone collapse. In most systems where cofilin has been investigated, however, the evidence generally suggests that inactivation of cofilin is required for collapse/ repulsion. For example, Lim-Kinase-mediated inhibition of cofilin is required for Sema3Aelicited growth cone collapse of DRG neurons (Aizawa et al. 2001). In contrast, treatment of chick DRGs with BDNF, a chemoattractive factor, induces an increase in filopodia number through a cofilin-dependent mechanism (Chen et al. 2006). Cofilin activity appears to be required for outgrowth, chemoattraction, and protrusion formation, and in most instances cofilin must be inhibited for growth cone collapse or repulsion.

Only one study reports a different role for cofilin in growth cone guidance and suggests a biphasic role in axon guidance (Wen et al. 2007). BMP7 elicits turning responses from Xenopus spinal axons by altering the activation state of cofilin through LIM kinase and Slingshot phosphatase. Within a few hours of plating, spinal axons were attracted to BMP7 gradients by a LIMK-dependent mechanism. However, after overnight culture, the axons were repelled by BMP7 by an SSH-dependent mechanism (Wen et al. 2007). Therefore, in this system, BMP7 chemoattraction requires inhibition of cofilin, while BMP7 repulsion requires active cofilin. These findings are opposite to the aforementioned studies in which cofilin activity appears associated with chemoattraction, and repulsion/collapse requires cofilin inhibition. There are at least two ways the apparent differences may be reconciled: BMP7 may activate a set of actin regulatory proteins that alter the output of cofilin activity and are not activated by Sema3A treatment, or Xenopus spinal axon growth cones may differ in some fundamental way from the types of growth cones employed for other studies that assayed cofilin in guidance responses. A cofilin biosensor that could be used in living neurons would help clarify the contexts in which cofilin might play positive or negative roles in growth cone guidance responses.

\section{Actin Depolymerizing Proteins}

Mical

One of the most exciting and important contributions to our understanding of how guidance cues affect actin remodeling has been the 
identification of Mical, an F-actin depolymerizing protein, as a component of the pathway that mediates the response to Semaphorinla by the Plexin A receptor (Terman et al. 2002; Hung et al. 2010). Mical was identified as a ligand for the conserved C2 cytoplasmic domain of Plexin A and could be coimmunoprecipitated with Plexin A. The Mical protein has multiple conserved domains and motifs including: a calponin homology " $\mathrm{CH}$ " domain (implicated in protein:protein interactions including $\mathrm{F}$-actin binding; a Lim domain; a proline-rich region; a coiled-coil region similar to the one found in ERM proteins; and an amino terminal monooxygenase domain (Terman et al. 2002). Mical binds to Plexin A through its c-terminal ERMlike coiled-coil domain (Hung et al. 2010).

Genetic analysis in Drosophila established that Mical functions in the Plexin A pathway during motor axon guidance (Terman et al. 2002). Interestingly, some of the milder Mical mutants survive and were found to exhibit severe defects in bristle morphology (Hung et al. 2010). Bristles are comprised of precisely arranged actin filament bundles and are formed by highly regulated actin assembly and crosslinking. The identification of dramatic bristle phenotypes in Mical mutants was an important clue that Mical likely regulated actin dynamics. Biochemical analyses indicated that Mical binds F-actin and F-actin bundles and that Mical disassembled both individual and bundled filaments (Hung et al. 2010). Surprisingly, this depolymerization activity required the redox enzymatic activity contained within the Mical monooxygenase domain as well as the coenzyme NADPH. Kinetic actin polymerization assays indicated that activated Mical reduced actin polymerization and drove F-actin depolymerization. Activated Mical also decreases the length and width of F-actin bundles. Mical function in either axon guidance or in controlling bristle morphology in vivo required the F-actin depolymerizing redox domain, the $\mathrm{CH}$ domain, and the c-terminal Plexin A interaction domain.

Put together, the Semaphorin-Plexin AMical pathway represents one of the clearest examples to date of how the spatiotemporal dynamics of F-actin are coupled to an axon guidance pathway. Mical colocalizes with F-actin in growth cones (Hung et al. 2010) and expression of activated Mical causes growth cones to acquire a more complex, highly branched morphology. Such complex morphologies are associated with growth cones pausing at choice points. Thus, it will be interesting to determine if the three vertebrate Mical orthologs also function in axon guidance and whether the Mical proteins function in other guidance responses.

\section{Monomer Binding Proteins}

\section{Profilin}

Unlike previously described actin-associated proteins, profilin and cyclase associated protein (CAP) bind to actin monomers (G-actin). Profilin is one of the most abundant proteins within cells (Kaiser et al. 1999) and serves multiple functions. First, profilin suppresses spontaneous actin nucleation in cells (Pollard and Borisy 2003; Pollard and Cooper 2009). Second, through interactions with other monomerbinding proteins, profilin promotes the exchange of ADP for ATP on monomers. Finally, profilin-bound ATP-actin provides a pool of polymerization-competent monomer that can be readily added to free barbed ends to support polymerization (Dominguez 2009). Profilin: actin complexes can bind through a distinct interface to polyproline-rich ligands, including N-WASP, WAVE, DAAM (and other formin superfamily proteins), and Ena. When complexed with these actin regulatory proteins, profilin:actin supports direct monomer transfer onto filament barbed ends to stimulate filament nucleation and elongation (Dominguez 2009).

Mutations in chickadee (chick), a Drosophila profilin homolog, were identified in a screen for mutants affecting motor axon outgrowth and navigation (Vactor et al. 1993; Wills et al. 1999a). Mutations in chick result in premature arrest of ISNb motor axons before they reach their targets, a phenotype similar to $A b l$ mutants (Wills et al. 1999b) and the opposite to what is observed in Ena mutants: ISNb axons bypassing their targets. A dosage-sensitive genetic interaction between chick and $A b l$ was 
E.W. Dent et al.

identified, indicating that they cooperate in guidance. However, it is somewhat unclear how chick cooperates with $A b l$ since the major known profilin-binding component of the pathway is Ena, which acts antagonistically to Abl. Perhaps the interaction between Ena and profilin and their regulation by $\mathrm{Abl}$ is more complex than predicted by in vitro biochemical analyses. Alternatively, other profilinbinding proteins, such as DAAM (Matusek et al. 2008), may function in ISNb axon guidance.

\section{CAP}

First identified in yeast, CAP proteins contain an n-terminal domain that binds and coactivates adenylyl cyclase (only in the yeast proteins), a proline-rich region that mediates interactions with $\mathrm{SH} 3$ domains, and a c-terminal domain that binds G-actin. In Drosophila, CAP is expressed in the developing nervous system (Wills et al. 2002). Mutations in CAP exhibit a potent transheterozygous interaction with $A b l$ to cause a specific axon guidance defect at the CNS midline, one not seen in either single heterozygous mutant (Wills et al. 2002). CAP also interacts genetically with SLIT during midline crossing. CAP appears to be in a biochemical complex with both $\mathrm{Abl}$ and profilin (Wills et al. 2002), consistent with earlier findings indicating that mammalian CAP can bind the Abl SH3 domain (Hubberstey and Mottillo 2002). The exact role of CAP in axon guidance and how it responds to signaling downstream of Robo and Abl remains unclear. CAP can act as a monomer sequestering protein (Hubberstey and Mottillo 2002), so it is possible that it functions to limit actin polymerization during some steps in axon navigation.

\section{Actin-nucleating Proteins}

In the last few years, several actin-nucleating proteins have been identified, and a subset of these is found in the developing brain of different model organisms. These proteins include the Arp2/3 complex (Shakir et al. 2008; Norris et al. 2009), spire (Schumacher et al. 2004), formin family proteins such as DAAM (Schumacher et al. 2004; Matusek et al. 2008; Hotulainen et al. 2009), and cordon-bleu (Ahuja et al. 2007).

Activation of the Arp2/3 complex, which nucleates new filaments off the sides of existing F-actin, is accomplished primarily by WASP / WAVE (also called "SCAR") proteins, which themselves are regulated by Rho GTPases and other signaling cascades. In Drosophila, loss of function of components in the Arp2/3 complex or its activator SCAR result in aberrant axonal morphology of commissural and longitudinal axons (Zallen et al. 2002). However, these defects may arise as a secondary consequence of other extensive defects in actin-driven developmental processes. To overcome phenotypes observed in the absence of Arp2/3 function, $\mathrm{Ng}$ and Luo performed analysis of single cell clones in developing mushroom body (MB) neurons of Drosophila and found that removal of an essential component of $\operatorname{Arp} 2 / 3$, or of WAVE, WASP, or both, resulted in MB neurons with no obvious axonal growth or morphological defects (Ng and Luo 2004). In C. elegans, removal of both WAVE and WASP, or components of the Arp2/3 complex, result in clear axon guidance defects, but do not affect the ability of axons to elongate (Shakir et al. 2008; Norris et al. 2009). Therefore, it appears that the Arp2/3 complex is dispensable for axon formation and outgrowth, but is required in specific guidance pathways.

The role of the Arp2/3 complex in axon outgrowth in mammals has been more difficult to define. In one study, expression of an Arp2/3 inhibitory construct in cultured hippocampal neurons caused no obvious changes in growth cone morphology and filopodia formation, but yielded significant increases in axon length and impaired responses to Sema3A (Strasser et al. 2004). A second study using both the Arp2/3 inhibitory strategy and siRNA against Arp2/3 subunits to remove Arp2/3 activity in primary hippocampal neurons also found that reduction in Arp2/3 activity caused increased axon elongation (Pinyol et al. 2007). A third study, however, found that RNAi-mediated depletion of Arp2/3 in neurons resulted in 
reduced filopodial and lamellipodial protrusion dynamics. It should be noted that while some key experiments (e.g., growth cone protrusion dynamics) were performed in primary hippocampal neurons, most of the data presented in this study were derived from the use of differentiated neuronal-like B35 cells that may or may not reflect the properties of primary neurons (Korobova and Svitkina 2008). It is possible that the inhibitory strategy used by Strasser et al. and Pinyol et al. was not fully effective in blocking Arp2/3 activity; however, the siRNA knockdown strategy used by Korobova and Svitkina depleted Arp2/3 only to about $40 \%$ of normal levels. Furthermore, Pinyol et al. used an Arp2/3 inhibitory construct and RNAi approaches that both yielded results consistent with those of Strasser and colleagues. It is also possible that other differences in experimental design such as the length of time in culture before and after transfection, prior to analysis, may be responsible for these different findings. Regardless of these differences, it is possible to conclude that, as in Drosophila and C. elegans, Arp2/3 is not essential for neurite and subsequent axon formation and elongation based on these various loss-of-function studies. Also, as is the case from the analysis of C. elegans Arp2/3 mutants (Norris et al. 2009), a reduction in Arp2/3 may compromise filopodial dynamics. Ultimately, it will be necessary to perform true loss-of-function analysis on Arp2/3 and its activators to evaluate the exact role of Arp2/3 in growth cone morphology and axon elongation in mammalian neurons.

While it is unclear whether all guidance responses involve Arp2/3-mediated nucleation, Sema3A and netrin likely utilize this pathway of actin assembly. Sema3A-induced growth cone repulsion is correlated with a decrease in intensity of the Arp2/3 complex and cortactin, and an associated increase in the intensity of fascin and myosin II (Brown and Bridgman 2009). Furthermore, as described above, neurons expressing an Arp2/3 inhibitory construct fail to respond properly to Sema3A (Strasser et al. 2004). Inhibition of N-WASP, an Arp2/3 activator, via expression of a dominant-negative construct in commissural neurons blocks the increase in filopodia and growth cone area observed normally after netrin stimulation (Shekarabi et al. 2005), suggesting that Arp2/3 may be required for netrin response.

It will be important to determine which nucleating activities are required for growth cone locomotion, axon guidance, or both. Furthermore, it is unclear whether there is functional overlap between the different families of actin nucleators (Arp2/3, spire, DAAM1, and cordon-blue). Finally, it will be interesting to define the roles of recently discovered nucleators, such as the neuronal-specific cordon-blue (Ahuja et al. 2007), in axon navigation.

\section{Actin/MT Cross-linking Proteins}

The coordination of actin and microtubule dynamics is of key importance during axon guidance. Several actin and microtubule crosslinking proteins, such as Drosophila pod-1 (dpod1), have been implicated in axon guidance. In cultured S2 cells, Dpod1 colocalizes with lamellar actin and MTs, while in neurons Dpod1 localizes to the tips of growing axons (Rothenberg et al. 2003). Both loss- and overexpression of Dpod1 cause defects in axon targeting (Rothenberg et al. 2003). It will be interesting to determine which guidance pathways utilize pod-1. MAP1B, discussed in the following section, is also an actin-microtubule cross-linking protein. MAP1B binds to F-actin (Togel et al. 1998; Noiges et al. 2002) and is implicated in netrin-1-mediated guidance (Del Rio et al. 2004). Spectraplakins are another actinmicrotubule linker family implicated in development. Expression data for the mammalian spectraplakin, ACF7, and genetic analyses of the Drosophila spectraplakin Shortstop (Shot), suggest that spectraplakin plays an important role in nervous system development (Bernier et al. 2000; Sanchez-Soriano et al. 2009). ACF7 and Shot regulate both microtubule organization and filopodia formation in the developing nervous system, suggesting they may function to coordinate the organization of both cytoskeletal networks during axonal growth (SanchezSoriano et al. 2009). 
E.W. Dent et al.

\section{MICROTUBULE-ASSOCIATED PROTEINS IN AXON GUIDANCE}

Another promising avenue of research, in addition to studying the intrinsic dynamics and distribution of MTs in growth cones, is understanding how microtubule-associated proteins (MAPs) are involved in axon guidance decisions (Fig. 3). There are many types of MAPs (see Table 2) that regulate distinct aspects of MT function, and many have been studied in great detail. However, there is relatively little work on how MAPs function specifically in axon guidance. We now touch upon recent studies that have implicated MAPs in growth cone turning and axon guidance decisions.

\section{Plus-End-Tracking Proteins (+TIPs)}

This set of proteins has the defining feature that they bind to the rapidly growing $(+)$ ends of
MTs (Akhmanova and Steinmetz 2008). When MTs convert from polymerizing to a depolymerizing state, that is, when they undergo "catastrophe," + TIP proteins dissociate from the MT. These proteins are particularly important because they are concentrated on the dynamic fraction of MTs that extend into the distal regions of the growth cone, and they are therefore in close proximity to guidance cue receptors. Thus, they may be some of the first MAPs to integrate signaling cascades induced by guidance cue receptor activation.

One of the first + TIP proteins implicated in axon guidance is CLASP (Lee et al. 2004), a CLIP (Cytoplasmic Linker Protein)-associated protein that is known to enhance MT rescue (the switch from depolymerization to polymerization) and stabilization (Galjart 2005). In a screen for interactors with Abl tyrosine kinase, it was discovered that Orbit/MAST
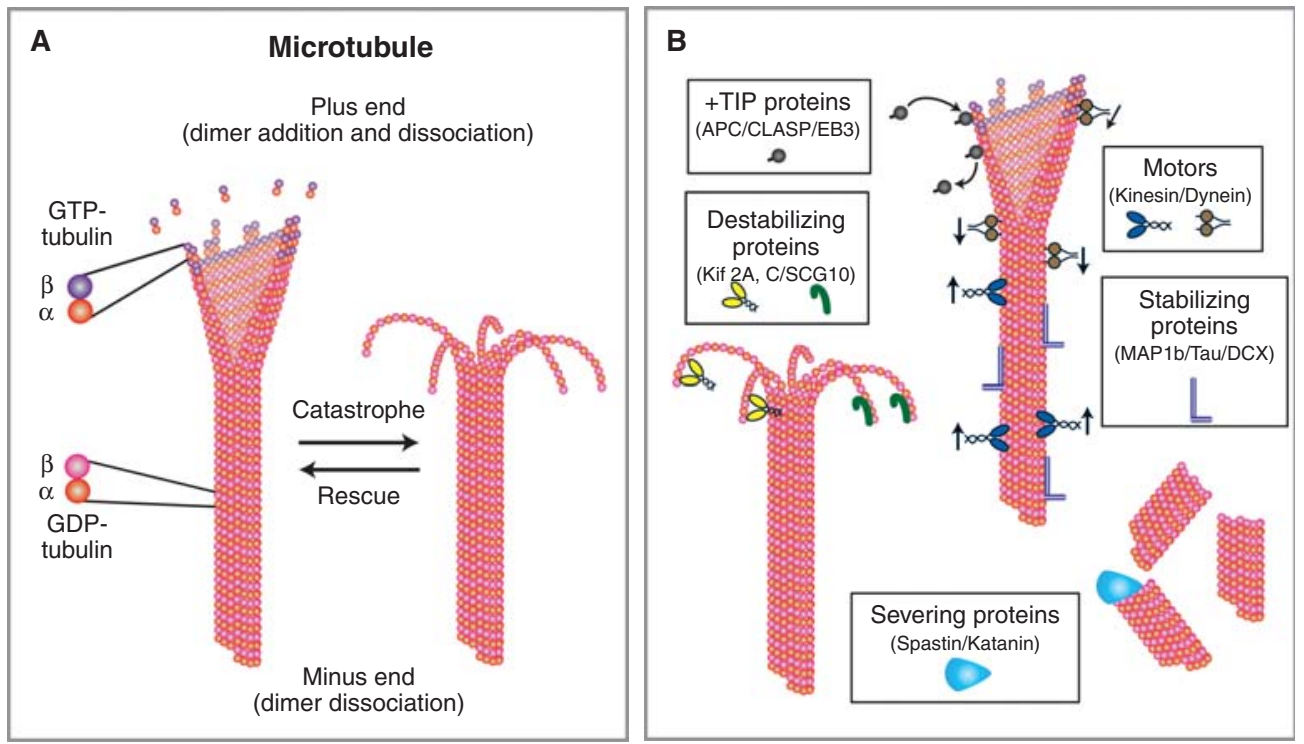

Figure 3. Structural characteristics of microtubules and microtubule-associated proteins. (A) Microtubules are polar polymers composed of a plus end, where dimer addition and dissociation occur, and a minus end where dimer dissociation can occur. In neurons the minus end of microtubules is often stabilized. Microtubule dynamics occur primarily through polymerization and depolymerization at the plus end. The conversion of microtubule growth to shrinkage is termed "catastrophe" and the conversion from shrinkage to growth is termed "rescue" in this figure. The nucleotide state of tubulin also changes soon after dimer addition (GTP $\rightarrow$ GDP). (B) As microtubules polymerize, they bind + TIP proteins at their plus ends. There are many structural microtubule-associated proteins (MAPs) that usually act to stabilize the microtubule. Motor proteins, such as the kinesin family of proteins and cytoplasmic dynein, also transport cargos along microtubules. Several proteins aid in the depolymerization of microtubules, while others can sever microtubules. 


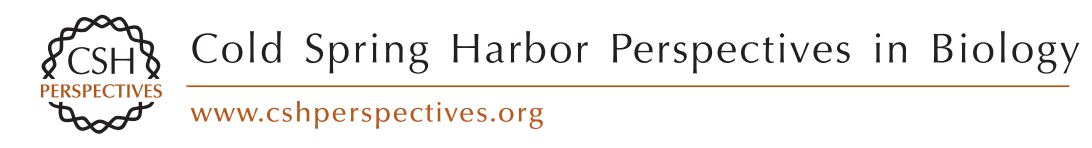

Table 2. Microtubule Regulators.

\begin{tabular}{|c|c|c|c|c|c|}
\hline Protein Family & Guidance Assay & $\begin{array}{c}\text { Result/Potential } \\
\text { Guidance Pathways }\end{array}$ & References & $\mathrm{P} / \mathrm{O} / \mathrm{B}$ & References \\
\hline \multicolumn{6}{|c|}{ Plus-End-Tracking Proteins (+TIPs) } \\
\hline APC & $\mathbf{M}(\mathrm{MR})$ & Active on side of turn & (Koester et al. 2007) & $+\mathrm{O} / \mathrm{P}+$ & $\begin{array}{l}\text { (Shi et al. 2004; Zhou et al. } \\
\text { 2004; Purro et al. 2008) }\end{array}$ \\
\hline APC2 & $\mathbf{I}(\mathrm{Gg}), \mathbf{S}(\mathrm{Gg})$ & $\begin{array}{l}\text { Active on side of turn/ } \\
\text { ephrin-A2 }\end{array}$ & (Shintani et al. 2009) & $+\mathrm{O}$ & (Shintani et al. 2009) \\
\hline CLASP & $\mathbf{I}(\mathrm{Dm})$ & Inactive on side of turn & (Lee et al. 2004) & $-\mathrm{O}$ & (Lee et al. 2004) \\
\hline EB1-3 & - & ??? & - & EB1 - comp. MAP1B & $\begin{array}{l}\text { (Jimenez-Mateos et al. } \\
\text { 2005) }\end{array}$ \\
\hline Lis1 & - & ??? & - & $\begin{array}{l}\text { EB3 - neuritogenesis } \\
+\mathrm{O}\end{array}$ & $\begin{array}{l}\text { (Geraldo et al. 2008) } \\
\text { (Tsai et al. 2005; Grabham } \\
\text { et al. 2007) }\end{array}$ \\
\hline Neuron Navigator & $\mathrm{C}$ & $\begin{array}{l}\text { KD shows no } \\
\text { preference to netrin }\end{array}$ & (Martinez-Lopez et al. 2005) & ??? & - \\
\hline Short Stop/ACF7 & I (Dm) & Required for repulsion & (Lee et al. 2007) & $+\mathrm{O}$ & $\begin{array}{l}\text { (Sanchez-Soriano et al. } \\
\text { 2009) }\end{array}$ \\
\hline \multicolumn{6}{|c|}{ Microtubule-stabilizing Proteins } \\
\hline CRMP family & $\mathbf{I}(\mathrm{Ce})$ & Disrupted axon tracts & (Hedgecock et al. 1985) & $+\mathrm{P} /+\mathrm{O}$ & $\begin{array}{l}\text { (Quinn et al. 2003; } \\
\text { Yoshimura et al. 2005) }\end{array}$ \\
\hline Dishevelled-1 & - & ??? & - & $+\mathrm{O}$ & $\begin{array}{l}\text { (Ciani et al. 2004; Purro } \\
\text { et al. 2008) }\end{array}$ \\
\hline $\begin{array}{l}\text { Doublecortin } \\
\quad \text { (anti-catastrophe) }\end{array}$ & I (MR) & Disrupted axon tracts & (Deuel et al. 2006) & $+\mathrm{O} /-\mathrm{B}$ & $\begin{array}{l}\text { (Koizumi et al. 2006; Bielas } \\
\text { et al. 2007) }\end{array}$ \\
\hline $\mathrm{mDia} 1 / 2 / 3$ & - & ??? & - & $+\mathrm{O}$ & (Arakawa et al. 2003) \\
\hline MAP1B & I (MR), M,S,C & $\begin{array}{l}\text { Active on side of turn/ } \\
\text { netrin }\end{array}$ & (Mack et al. 2000) & $+\mathrm{O} /-\mathrm{B}$ & $\begin{array}{l}\text { (Gonzalez-Billault et al. } \\
\text { 2001) }\end{array}$ \\
\hline & & & $\begin{array}{l}\text { (Meixner et al. 2000) } \\
\text { (Del Rio et al. 2004) }\end{array}$ & & (Bouquet et al. 2004) \\
\hline \multirow[t]{2}{*}{ MAP2c } & - & ??? & - & $+\mathrm{O}$ & (Dehmelt et al. 2003) \\
\hline & & & & & Continued \\
\hline
\end{tabular}




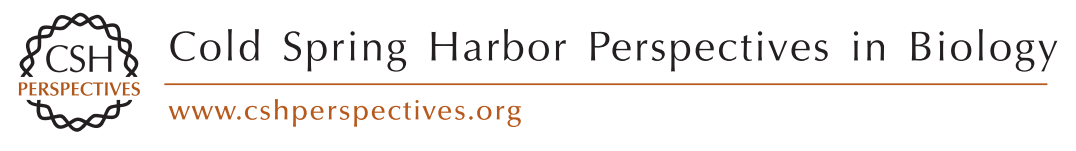

\begin{tabular}{|c|c|c|c|c|c|}
\hline Protein Family & Guidance Assay & $\begin{array}{c}\text { Result/Potential } \\
\text { Guidance Pathways }\end{array}$ & References & $\mathrm{P} / \mathrm{O} / \mathrm{B}$ & References \\
\hline Tau & - & ??? & - & $+\mathrm{O} /-\mathrm{B}$ & $\begin{array}{l}\text { (Takei et al. 2000; Dawson } \\
\text { et al. 2001; Qiang et al. } \\
\text { 2009) }\end{array}$ \\
\hline \multicolumn{6}{|c|}{ Microtubule-destabilizing Proteins } \\
\hline SCG10 & - & ??? & - & $+\mathrm{O}$ & $\begin{array}{l}\text { (Suh et al. 2004; Morii et al. } \\
\text { 2006; Tararuk et al. } \\
\text { 2006; Li et al. 2009) }\end{array}$ \\
\hline SCLIP & - & ??? & - & $-B$ & (Poulain and Sobel 2007) \\
\hline Kinesin 13 (Kif2A, C) & - & ??? & - & $-B$ & (Homma et al. 2003) \\
\hline \multicolumn{6}{|c|}{ Microtubule-severing Proteins } \\
\hline Katanin & - & ??? & - & $+/-\mathrm{O}$ & $\begin{array}{l}\text { (Karabay et al. 2004; Yu } \\
\text { et al. 2008) }\end{array}$ \\
\hline Spastin & - & ??? & - & $+\mathrm{O} /+\mathrm{B}$ & $\begin{array}{l}\text { (Wood et al. 2006; Yu et al. } \\
\text { 2008; Riano et al. 2009) }\end{array}$ \\
\hline Dynein/Dynactin* & $\mathbf{S}(\mathrm{MR})$ & $\begin{array}{l}\text { Substrate border } \\
\text { turning defects }\end{array}$ & (Myers et al. 2006) & & \\
\hline $\begin{array}{l}\text { Kinesin-5 } \\
\text { Guidance Assays }\end{array}$ & $\mathbf{S}(\mathrm{MR})$ & Inactive on side of turn & (Nadar et al. 2008) & $-\mathrm{O}$ & (Nadar et al. 2008) \\
\hline $\begin{array}{l}\text { (S) Substrate-Stripe, }( \\
\text { assay, }(\mathbf{M}) \text { Micro-CALI. } \\
\left(^{*}\right) \text { also considered a } \\
(\mathbf{P} / \mathbf{O} / \mathbf{B}) \text { Polarity/Ou }\end{array}$ & $\begin{array}{l}\text { Collagen Gel, }(\mathbf{C}-\mathbf{R}) \mathrm{c} \\
\text { IP protein. } \\
\text { owth/Branching. }\end{array}$ & apse/retraction, (I) In vivo, ( & C. elegans, (Dm) Drosof & afish, $(G g)$ chicken & use/rat, (Xl) Xenopus, (P) pipet \\
\hline
\end{tabular}


(the Drosophila homolog of CLASP) mutants had ectopic CNS midline crossing defects (Lee et al. 2004). Since midline crossing is tightly influenced by Slit/Robo signaling through $\mathrm{Abl}$, this study placed Orbit/MAST downstream of this guidance cue. These Orbit/ MAST loss-of-function mutants also have defects in ISNb motor neurons, causing them to stop short and innervate incorrect muscles. The vertebrate homolog of Orbit, CLASP, was expressed in Xenopus spinal neurons, where it was found to be highly enriched on dynamic MTs within the growth cone. These MTs were capable of extending into the peripheral regions of the growth cone and into filopodia. Interestingly, when CLASP was overexpressed, it caused MTs to form loops within the growth cone, resulting in growth cone pausing. This is an intriguing study that implicates a + TIP protein in axon guidance, but questions remain. It is unclear why a protein implicated in MT rescue and stabilization would be activated on the side of the growth cone exposed to the highest concentration of Slit, since Slit has been shown to cause growth cone collapse and turning when applied as a gradient (Piper et al. 2006). However, another + TIP protein, Shot/ACF7, is also required for proper repulsion at the Drosophila CNS midline, indicating that + TIPs may function in a heretofore unknown way to allow growth cone repulsion (Lee et al. 2007).

In contrast, recent work implicates another + TIP protein, APC (adenomatous polyposis coli), as a positive regulator of growth cone turning (Koester et al. 2007). This study used micro-CALI (chromaphore-assisted laser inactivation) with two different antibodies to show that inactivating a region of APC known to associate with extending MTs induced turning away from the laser-treated side. In contrast, inactivation of another region of APC known to be involved in $\beta$-catenin binding, induced turning toward the laser treated side, presumably by enhancing APC binding to MTs. The authors argue that these results show that when APC is actively associated with MTs, the growth cone turns toward that side of the growth cone (Koester et al. 2007). Thus, it would be predicted that local guidance signals change the association of APC with MTs, resulting in turning either toward or away from the signal, depending on whether the guidance cue is attractive or repulsive. Recently, an intriguing study implicated APC2, the second APC family member, in the guidance of retinotectal neurons. Knockdown of APC2 results in guidance defects in response to ephrin-A2, both in a stripe assay and in vivo (Shintani et al. 2009). Furthermore, APC2 overexpression stabilizes MTs, and guidance defects following shRNA treatment could be rescued by stabilizing MTs with taxol. This work suggests that APC2 plays a role in axon guidance through the stabilization of MTs. Since APC2 was shown to be preferentially expressed in the nervous system, it may be the major form of APC that regulates axon outgrowth and guidance (Shintani et al. 2009). However, APC2 does not contain the region of APC implicated in MTor + TIP binding, suggesting it functions in a complex with other MAPs.

For the rest of the +TIP protein family, including CLIP proteins, EB proteins, Lis1, and Neuronal Navigator 1 (mNav1), less is known about their function in axon guidance. However, mNav1 has been implicated in axon guidance in response to netrin-1 (MartinezLopez et al. 2005). Knocking down mNav1 with RNAi in rhombic lip explants decreased their preferential growth toward netrin-secreting explants. Thus, mNav1 may be important for neurons to turn toward a positive guidance cue. Generally speaking, since many + TIP proteins are important for MT stabilization, either through promotion of MT growth, anti-catastrophe activity, rescue activity, stabilization, or linking MTs to the actin cytoskeleton or cortex, their activity will likely be associated with the attractive guidance cues, and their inactivation with repulsive cues. However, this hypothesis remains to be tested.

\section{Microtubule-stabilizing Proteins (Structural MAPs)}

Given the hypothesis that axon guidance and growth cone turning depend upon regulating MT dynamics, it is not surprising that the few 
E.W. Dent et al.

microtubule stabilizing proteins (MAPs) that have been implicated in guidance decisions are likely to be active on the side of the growth cone toward which it turns. Indeed, in a number of studies, MAP1B has been shown to play a role in axon guidance. An earlier study of the first MAP1B null mouse demonstrated that MAP1B is essential for corpus callosum development (Meixner et al. 2000). This suggests that there is an axon guidance defect but does not rule out that MAP1B deficiency could slow callosal axon outgrowth, resulting in agenesis of the callosum. However, another study using micro-CALI implicated MAP1B directly in growth cone turning (Mack et al. 2000). By using an antibody to a specific MAP1B phospho-epitope, it was shown that inactivation of phospho-MAP1B on one side of the growth cone caused turning in the opposite direction, presumably through destabilization of MTs on the laser-exposed side. A more recent study placed MAP1B in the netrin signaling cascade by showing that MAP1B null axons were deficient in their outgrowth response to netrin 1 , and that netrin addition resulted in phosphorylation of MAP1B through GSK3 and cdk5 (Del Rio et al. 2004). Thus, it is likely that MAP1B plays a prominent role in stabilizing MTs preferentially on one side of the growth cone during chemoattractive turning. Future studies will have to determine if it is downstream of other guidance pathways.

In addition to MAP1B, there are other proteins that specifically stabilize MTs in neurons. Although they have been shown to function in outgrowth, branching, and polarity of neurons, very few studies have been undertaken to determine if these proteins function in axon guidance. For example, the CRMP family of proteins appears to be an important downstream component of the Sema3A signaling pathway and is essential for the growth cone collapse response to bath-applied Sema3A. However, there have been no studies in mammalian neurons that show it is directly involved in growth cone turning, although it is known to be important for axon outgrowth and polarity (Quinn et al. 2003; Yoshimura et al. 2005). Nevertheless, a few early studies on Unc-33, the C. elegans homolog of CRMP, implicated that its loss resulted in axon guidance errors in several pathways (Hedgecock et al. 1985; Li et al. 1992). Other classic MAPs, such as MAP2c and Tau, also play important roles in axon outgrowth but have yet to be shown to function directly in axon guidance pathways. Doublecortin is a MT-stabilizing protein that when knocked out results in disrupted axon tracts (Deuel et al. 2006). However, no direct growth cone turning or guidance assays have tested doublecortin function downstream of specific guidance cues.

\section{Microtubule-destabilizing and Severing Proteins}

Based on the work mentioned above that seems to favor MT stabilization on the side of the growth cone toward which it turns, one would predict that MT destabilizing proteins would be active on the opposite side of the growth cone, or inactivated on the turning side. Unfortunately, there are to date no data arguing for or against this hypothesis. Nevertheless, the two families of MT destabilizing proteins in neurons, the stathmin and kinesin 13 families, have been studied in some detail, and although their function in axon guidance has not been defined, they do affect axon outgrowth and branching (Homma et al. 2003; Suh et al. 2004; Morii et al. 2006; Tararuk et al. 2006; Poulain and Sobel 2007; Li et al. 2009). Interestingly, it appears that their destabilizing activity must be tightly regulated: too much and MT levels in the neurons fall, inhibiting outgrowth; too little and MTs grow to the tips of growth cones and form looped structures, also resulting in less outgrowth due to growth cone pausing.

Overexpression or knockdown of MT severing proteins produces similar phenotypes to overexpression or knockdown of MT destabilizing proteins. If the two known MT severing proteins in neurons, spastin and katanin, are highly overexpressed, they result in diminished axon/ neurite outgrowth due to increased severing of MTs in axons (Karabay et al. 2004; Riano et al. 2009). Knocking them down in neurons can result in stunted axons as well. Interestingly, spastin appears to play a major role not in 
axon outgrowth, but in axon branching. Overexpression of spastin results in a prominent increase in axonal branches (Yu et al. 2008). It will be interesting to determine if either of these proteins is required for axon guidance decisions since they are present in growth cones as well as axon shafts.

\section{Microtubule Motor Proteins}

MT motor proteins are best known for shuttling material either anterogradely, toward the growth cone (kinesins), or retrogradely, toward the cell body (dynein). However, as noted above for the kinesin 13 family, they can also destabilize MTs at their +ends. Conversely, cytoplasmic dynein can also act as a + TIP protein, associating with the rapidly growing ends of MTs. Although these proteins have not been extensively studied in the context of axon guidance and growth cone turning, there are hints that they may function in these processes. The first observations implicating dynein in axon guidance were from a study in Drosophila showing that a dynein light chain mutant had disrupted sensory axon projections (Phillis et al. 1996).

More recent data indicate that dynein may be functioning antagonistically with myosin II and kinesin 5 in growth cones (Myers et al. 2006; Nadar et al. 2008). Dynein is important for MTs to extend into the distal-most regions of the growth cone, including filopodia (Myers et al. 2006; Grabham et al. 2007). To do this, however, MTs must beat the constant myosinII-dependent retrograde flow of actin. Furthermore, kinesin 5 appears to be concentrated in the transition zone of the growth cone and when active appears to inhibit MT entry into distal regions of the growth cone (Nadar et al. 2008). How would disruption of either dynein or kinesin 5 activity affect growth cone turning? Interestingly, when kinesin 5 is inhibited with an allosteric inhibitor (monastrol), growth cones ignore borders of laminin/poly-lysine, which they normally respond to by turning (Nadar et al. 2008). Dynein inhibition, via siRNA directed against dynein heavy chain, resulted in the decreased ability of growth cones to turn at such borders (Myers et al. 2006).
Although both of these studies implicate dynein and kinesin 5 in growth cone turning, it is still unclear how dynein- or kinesin-depleted neurons respond to attractive or repulsive guidance cues presented in soluble form. Based on these studies, it is likely that dynein, kinesin 5, and probably other kinesins would serve important functions in growth cone guidance.

\section{A WORKING MODEL FOR CYTOSKELETAL FUNCTION IN AXON GUIDANCE}

Great strides have been made in recent years elucidating the roles that the cytoskeleton plays in axon outgrowth and guidance. Although presenting a model necessarily oversimplifies the results of the numerous studies we have described in this review, a model provides a template for guiding future experiments. Thus, we present the cytoskeleton in a turning growth cone and outline three regions where actin and microtubule functions may be particularly important for integrating signals downstream of guidance cues (Fig. 4). This includes cytoskeletal events that may be occurring in response to a gradient of a positive guidance cue (in gray). Such cytoskeletal events may be reversed if the growth cone is exposed to a gradient of a negative guidance cue; however, complicating matters is the possibility that attractive and repulsive guidance may involve separate sets of cytoskeletal-associated proteins. Thus, we postulate events that may occur during both protrusion of the growth cone toward a positive guidance cue, and retraction of the growth cone on the side away from the cue.

During protrusion of the growth cone toward the positive guidance cue (Fig. 4B), it is likely that both actin-nucleating proteins and barbed-end binding proteins (tip complex proteins) are activated to coordinate actinbased protrusion of the growth cone. As mentioned above, actin severing may also be up-regulated to provide more actin filament free ends for protrusive growth. Further back in the growth cone, potentially in the transition zone, integration of the actin and MT networks likely occurs (Fig. 4C). This stage of cytoskeletal integration may be critical for 
E.W. Dent et al.
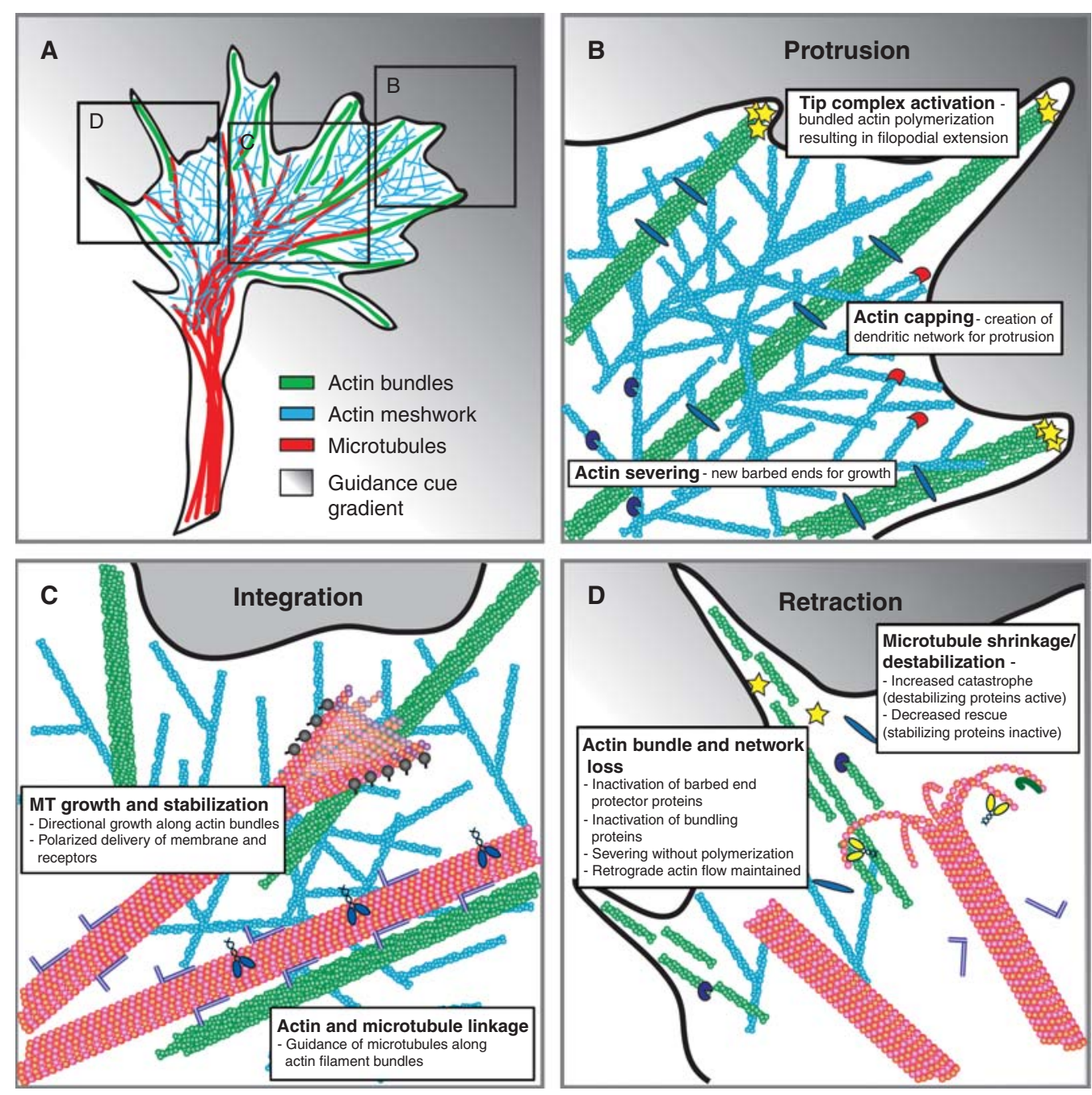

Figure 4. A working model of cytoskeletal dynamics in a growth cone exposed to a gradient of a positive guidance cue. (A) A schematic of a growth cone that includes actin bundles (green), an actin meshwork (blue), and microtubules (red). The guidance cue gradient (gray) is high in the upper right of the figure, toward which the growth cone is turning. Boxed regions of the growth cone are magnified in subsequent panels. $(B)$ This region of the growth cone is undergoing protrusion. Protrusion is due to activation of barbed-end binding proteins and actin nucleators, resulting in protrusion of filopodia and lamellipodia, respectively. Actin severing can also occur, resulting in new barbed ends for growth. $(C)$ This region of the growth cone is where the actin and microtubule cytoskeleton coordinate their activities, resulting in directed outgrowth. F-actin bundles can guide microtubules. The increased microtubule polymerization/stabilization on one side of the growth cone may favor polarized delivery of materials, which would subsequently favor growth in a particular direction. $(D)$ This region of the growth cone is undergoing retraction. Actin bundles and dendritic networks are disassembled, potentially through the inactivation of barbed-end binding and actin bundling proteins, increased severing of F-actin without subsequent polymerization and continued myosin-driven retrograde actin flow. Microtubules may undergo increased catastrophe or decreased rescue, resulting in their departure from this side of the growth cone. Importantly, several of the cytoskeletal interactions outlined in this model are suggestions based on the current literature but have yet to be documented experimentally. 
The Growth Cone Cytoskeleton in Axon Outgrowth and Guidance

directed outgrowth because several studies show that disrupting either MT stabilization or interactions between MTs and F-actin can be disruptive to growth cone turning, but not necessarily to axon outgrowth. Disassembly of the actin and MT cytoskeleton is also continuously taking place in an actively translocating growth cone and may be favored on the side of the growth cone opposite a chemoattractive gradient (Fig. 4D), or on the side of a growth cone facing a chemorepulsive gradient. Such retraction is likely to involve the inactivation of actin barbed-end protector and actin bundling proteins, accompanied by actin severing without subsequent polymerization. Furthermore, MT destabilization and catastrophe (and/or decreased rescue) are likely to be favored in retracting regions of the growth cone.

The coordination of all of these events is required to properly guide neurons to their correct targets during development. However, because there have been relatively few high resolution live-cell imaging studies of the cytoskeleton during growth cone turning, it is still unclear if these postulated events are necessary or sufficient to induce turning. Furthermore, we must remember that although direct manipulation of the cytoskeleton shows us how the growth cone "can" respond, it does not necessarily show how the growth cone "does" respond to guidance cues under natural conditions. Therefore, it will be critical to determine how growth cone turning occurs in response to guidance cues known to be responsible for specific axon guidance decisions in the organism, and ultimately to observe these events in vivo as they unfold during neural development.

\section{ACKNOWLEDGMENTS}

The authors would like to apologize for any omissions or misinterpretations that may have occurred in the article. The authors were supported by the following sources: NIH NS064014 (EWD), Dana Foundation (EWD), Whitehall Foundation (EWD), NIH GM068678 (FBG).

\section{REFERENCES}

Ahuja R, Pinyol R, Reichenbach N, Custer L, Klingensmith J, Kessels MM, Qualmann B. 2007. Cordon-bleu is an actin nucleation factor and controls neuronal morphology. Cell 131: 337-350.

Aigner L, Arber S, Kapfhammer JP, Laux T, Schneider C, Botteri F, Brenner HR, Caroni P. 1995. Overexpression of the neural growth-associated protein GAP-43 induces nerve sprouting in the adult nervous system of transgenic mice. Cell 83: 269-278.

Aizawa H, Wakatsuki S, Ishii A, Moriyama K, Sasaki Y, Ohashi K, Sekine-Aizawa Y, Sehara-Fujisawa A, Mizuno K, Goshima Y, et al. 2001. Phosphorylation of cofilin by LIM-kinase is necessary for semaphorin 3A-induced growth cone collapse. Nat Neurosci 4: 367-373.

Akhmanova A, Steinmetz MO. 2008. Tracking the ends: a dynamic protein network controls the fate of microtubule tips. Nat Rev Mol Cell Biol 9: 309-322.

Andrews GL, Tanglao S, Farmer WT, Morin S, Brotman S, Berberoglu MA, Price H, Fernandez GC, Mastick GS, Charron F, et al. 2008. Dscam guides embryonic axons by Netrin-dependent and -independent functions. Development 135: 3839-3848.

Arai A, Spencer JA, Olson EN. 2002. STARS, a striated muscle activator of Rho signaling and serum response factordependent transcription. J Biol Chem 277: 2445324459.

Arakawa Y, Bito H, Furuyashiki T, Tsuji T, Takemoto-Kimura S, Kimura K, Nozaki K, Hashimoto N, Narumiya S. 2003. Control of axon elongation via an SDF-1alpha/Rho/ $\mathrm{mDia}$ pathway in cultured cerebellar granule neurons. J Cell Biol 161: 381-391.

Aratyn YS, Schaus TE, Taylor EW, Borisy GG. 2007. Intrinsic dynamic behavior of fascin in filopodia. Mol Biol Cell 18: 3928-3940.

Argaw A, Duff G, Boire D, Ptito M, Bouchard JF. 2008. Protein kinase A modulates retinal ganglion cell growth during development. Exp Neurol 211: 494-502.

Ball LJ, Jarchau T, Oschkinat H, Walter U. 2002. EVH1 domains: structure, function and interactions. FEBS Lett 513: 45-52.

Barrientos T, Frank D, Kuwahara K, Bezprozvannaya S, Pipes GC, Bassel-Duby R, Richardson JA, Katus HA, Olson EN, Frey N. 2007. Two novel members of the ABLIM protein family, ABLIM-2 and -3, associate with STARS and directly bind F-actin. J Biol Chem 282: 8393-8403.

Barzik M, Kotova TI, Higgs HN, Hazelwood L, Hanein D, Gertler FB, Schafer DA. 2005. Ena/VASP proteins enhance actin polymerization in the presence of barbed end capping proteins. J Biol Chem 280: 28653-28662.

Bashaw GJ, Kidd T, Murray D, Pawson T, Goodman CS. 2000. Repulsive axon guidance: Abelson and Enabled play opposing roles downstream of the roundabout receptor. Cell 101: 703-715.

Bashaw GJ, Klein R. 2010. Signaling from axon guidance receptors. Cold Spring Harb Perspect Biol 2: a001941.

Bear JE, Gertler FB. 2009. Ena/VASP: towards resolving a pointed controversy at the barbed end. J Cell Sci 122: 1947-1953. 


\section{E.W. Dent et al.}

Bear JE, Loureiro JJ, Libova I, Fassler R, Wehland J, Gertler FB. 2000. Negative regulation of fibroblast motility by Ena/VASP proteins. Cell 101: 717-728.

Bear JE, Svitkina TM, Krause M, Schafer DA, Loureiro JJ, Strasser GA, Maly IV, Chaga OY, Cooper JA, Borisy GG, et al. 2002. Antagonism between Ena/VASP proteins and actin filament capping regulates fibroblast motility. Cell 109: 509-521.

Bentley D, Toroian-Raymond A. 1986. Disoriented pathfinding by pioneer neurone growth cones deprived of filopodia by cytochalasin treatment. Nature 323: $712-$ 715.

Bernier G, Pool M, Kilcup M, Alfoldi J, De Repentigny Y, Kothary R. 2000. Acf7 (MACF) is an actin and microtubule linker protein whose expression predominates in neural, muscle, and lung development. Dev Dyn 219: 216-225.

Bialkowska K, Saido TC, Fox JE. 2005. SH3 domain of spectrin participates in the activation of Rac in specialized calpain-induced integrin signaling complexes. J Cell Sci 118: 381-395.

Bielas SL, Serneo FF, Chechlacz M, Deerinck TJ, Perkins GA, Allen PB, Ellisman MH, Gleeson JG. 2007. Spinophilin facilitates dephosphorylation of doublecortin by PP1 to mediate microtubule bundling at the axonal wrist. Cell 129: $579-591$.

Bouquet C, Soares S, von Boxberg Y, Ravaille-Veron M, Propst F, Nothias F. 2004. Microtubule-associated protein $1 \mathrm{~B}$ controls directionality of growth cone migration and axonal branching in regeneration of adult dorsal root ganglia neurons. J Neurosci 24: 7204-7213.

Bouchard JF, Horn KE, Stroh T, Kennedy TE. 2008. Depolarization recruits DCC to the plasma membrane of embryonic cortical neurons and enhances axon extension in response to netrin-1. J Neurochem 107: 398-417.

Bouchard JF, Moore SW, Tritsch NX, Roux PP, Shekarabi M, Barker PA, Kennedy TE. 2004. Protein kinase A activation promotes plasma membrane insertion of DCC from an intracellular pool: A novel mechanism regulating commissural axon extension. J Neurosci 24: 3040-3050.

Bradley WD, Koleske AJ. 2009. Regulation of cell migration and morphogenesis by Abl-family kinases: emerging mechanisms and physiological contexts. J Cell Sci 122: 3441-3454.

Breitsprecher D, Kiesewetter AK, Linkner J, Urbanke C, Resch GP, Small JV, Faix J. 2008. Clustering of VASP actively drives processive, $\mathrm{WH} 2$ domain-mediated actin filament elongation. $E M B O J$ 27: 2943-2954.

Brown JA, Bridgman PC. 2009. Disruption of the cytoskeleton during Semaphorin 3A induced growth cone collapse correlates with differences in actin organization and associated binding proteins. Devel Neurobio 69: 633-646.

Brown JA, Wysolmerski RB, Bridgman PC. 2009. Dorsal root ganglion neurons react to semaphorin $3 \mathrm{~A}$ application through a biphasic response that requires multiple myosin II isoforms. Mol Biol Cell 20: 1167-1179.

Buck KB, Zheng JQ. 2002. Growth cone turning induced by direct local modification of microtubule dynamics. J Neurosci 22: 9358-9367.

Burnette DT, Ji L, Schaefer AW, Medeiros NA, Danuser G, Forscher P. 2008. Myosin II activity facilitates microtubule bundling in the neuronal growth cone neck. Dev Cell 15: 163-169.

Carlier MF, Laurent V, Santolini J, Melki R, Didry D, Xia GX, Hong Y, Chua NH, Pantaloni D. 1997. Actin depolymerizing factor $(\mathrm{ADF} / \mathrm{cofilin})$ enhances the rate of filament turnover: implication in actin-based motility. J Cell Biol 136: $1307-1322$.

Challacombe JF, Snow DM, Letourneau PC. 1997. Dynamic microtubule ends are required for growth cone turning to avoid an inhibitory guidance cue. J Neurosci 17: 3085-3095.

Chan AY, Bailly M, Zebda N, Segall JE, Condeelis JS. 2000. Role of cofilin in epidermal growth factor-stimulated actin polymerization and lamellipod protrusion. $J$ Cell Biol 148: 531-542.

Chang C, Adler CE, Krause M, Clark SG, Gertler FB, TessierLavigne M, Bargmann CI. 2006. MIG-10/Lamellipodin and AGE-1/PI3K Promote Axon Guidance and Outgrowth in Response to Slit and Netrin. Curr Biol 16: $854-862$.

Chen N, Furuya S, Shinoda Y, Yumoto M, Ohtake A, Sato K, Doi H, Hashimoto Y, Kudo Y, Higashi H. 2003. Extracellular carbohydrate-signal triggering cAMP-dependent protein kinase-dependent neuronal actin-reorganization. Neuroscience 122: 985-995.

Chen TJ, Gehler S, Shaw AE, Bamburg JR, Letourneau PC. 2006. Cdc42 participates in the regulation of $\mathrm{ADF} /$ cofilin and retinal growth cone filopodia by brain derived neurotrophic factor. J Neurobiol 66: 103-114.

Chereau D, Dominguez R. 2006. Understanding the role of the G-actin-binding domain of Ena/VASP in actin assembly. J Struct Biol 155: 195-201.

Chien CB, Rosenthal DE, Harris WA, Holt CE. 1993. Navigational errors made by growth cones without filopodia in the embryonic Xenopus brain. Neuron 11: 237-251.

Ciani L, Krylova O, Smalley MJ, Dale TC, Salinas PC. 2004. A divergent canonical WNT-signaling pathway regulates microtubule dynamics: dishevelled signals locally to stabilize microtubules. J Cell Biol 164: 243-253.

Cohan CS, Welnhofer EA, Zhao L, Matsumura F, Yamashiro S. 2001. Role of the actin bundling protein fascin in growth cone morphogenesis: localization in filopodia and lamellipodia. Cell Motil Cytoskeleton 48: 109-120.

Colavita A, Culotti JG. 1998. Suppressors of ectopic UNC-5 growth cone steering identify eight genes involved in axon guidance in Caenorhabditis elegans. Dev Biol 194: $72-85$.

Comer AR, Ahern-Djamali SM, Juang JL, Jackson PD, Hoffmann FM. 1998. Phosphorylation of Enabled by the Drosophila Abelson tyrosine kinase regulates the in vivo function and protein-protein interactions of Enabled. Mol Cell Biol 18: 152-160.

Davis DA, Wilson MH, Giraud J, Xie Z, Tseng HC, England C, Herscovitz H, Tsai LH, Delalle I. 2009. Capzb2 interacts with beta-tubulin to regulate growth cone morphology and neurite outgrowth. PLoS Biol 7: e1000208.

Dawson HN, Ferreira A, Eyster MV, Ghoshal N, Binder LI, Vitek MP. 2001. Inhibition of neuronal maturation in primary hippocampal neurons from tau deficient mice. J Cell Sci 114: 1179-1187. 
The Growth Cone Cytoskeleton in Axon Outgrowth and Guidance

De Arcangelis A, Georges-Labouesse E, Adams JC. 2004 Expression of fascin-1, the gene encoding the actinbundling protein fascin-1, during mouse embryogenesis. Gene Expr Patterns 4: 637-643.

Dehmelt L, Smart FM, Ozer RS, Halpain S. 2003. The role of microtubule-associated protein $2 \mathrm{c}$ in the reorganization of microtubules and lamellipodia during neurite initiation. J Neurosci 23: 9479-9490.

Del Rio JA, Gonzalez-Billault C, Urena JM, Jimenez EM, Barallobre MJ, Pascual M, Pujadas L, Simo S, La Torre A, Wandosell F, et al. 2004. MAP1B is required for Netrin 1 signaling in neuronal migration and axonal guidance. Curr Biol 14: 840-850.

Dent EW, Barnes AM, Tang F, Kalil K. 2004. Netrin-1 and semaphorin $3 \mathrm{~A}$ promote or inhibit cortical axon branching, respectively, by reorganization of the cytoskeleton. J Neurosci 24: 3002-3012.

Dent EW, Gertler FB. 2003. Cytoskeletal dynamics and transport in growth cone motility and axon guidance. Neuron 40: 209-227.

Dent EW, Kalil K. 2001. Axon branching requires interactions between dynamic microtubules and actin filaments. J Neurosci 21: 9757-9769.

Deuel TA, Liu JS, Corbo JC, Yoo SY, Rorke-Adams LB, Walsh CA. 2006. Genetic interactions between doublecortin and doublecortin-like kinase in neuronal migration and axon outgrowth. Neuron 49: 41-53.

Dickson TC, Mintz CD, Benson DL, Salton SR. 2002. Functional binding interaction identified between the axonal CAM L1 and members of the ERM family. J Cell Biol 157: 1105-1112.

Dickson BJ, Gilestro GF. 2006. Regulation of commissural axon pathfinding by slit and its Robo receptors. Annu Rev Cell Dev Biol 22: 651-675.

Dominguez R. 2009. Actin filament nucleation and elongation factors-structure-function relationships. Crit Rev Biochem Mol Biol 44: 351-366.

Drees F, Gertler F. 2008. Ena/VASP: proteins at the tip of the nervous system. Curr Opin Neurobiol 18: 53-59.

Dwivedy A, Gertler FB, Miller J, Holt CE, Lebrand C. 2007. Ena/VASP function in retinal axons is required for terminal arborization but not pathway navigation. Development 134: 2137-2146.

Elkins T, Zinn K, McAllister L, Hoffmann FM, Goodman CS. 1990. Genetic analysis of a Drosophila neural cell adhesion molecule: interaction of fasciclin I and Abelson tyrosine kinase mutations. Cell 60: 565-575.

Endo M, Ohashi K, Sasaki Y, Goshima Y, Niwa R, Uemura T, Mizuno K. 2003. Control of growth cone motility and morphology by LIM kinase and Slingshot via phosphorylation and dephosphorylation of cofilin. J Neurosci 23: 2527-2537.

Erkman L, Yates PA, McLaughlin T, McEvilly RJ, Whisenhunt T, O'Connell SM, Krones AI, Kirby MA, Rapaport DH, Bermingham JR, et al. 2000. A POU domain transcription factor-dependent program regulates axon pathfinding in the vertebrate visual system. Neuron 28: 779-792.

Ferron F, Rebowski G, Lee SH, Dominguez R. 2007. Structural basis for the recruitment of profilin-actin complexes during filament elongation by Ena/VASP. EMBO J 26: 4597-4606.

Forsthoefel DJ, Liebl EC, Kolodziej PA, Seeger MA. 2005. The Abelson tyrosine kinase, the Trio GEF and Enabled interact with the Netrin receptor Frazzled in Drosophila. Development 132: 1983-1994.

Fritz JL, VanBerkum MFA. 2002. Regulation of rho family GTPases is required to prevent axons from crossing the midline. Dev Biol 252: 46-58.

Galjart N. 2005. CLIPs and CLASPs and cellular dynamics. Nat Rev Mol Cell Biol 6: 487-498.

Gallo G. 2006. RhoA-kinase coordinates F-actin organization and myosin II activity during semaphorin-3Ainduced axon retraction. J Cell Sci 119: 3413-3423.

Garbe DS, Das A, Dubreuil RR, Bashaw GJ. 2007a. betaSpectrin functions independently of Ankyrin to regulate the establishment and maintenance of axon connections in the Drosophila embryonic CNS. Development 134: 273-284.

Garbe DS, O’Donnell M, Bashaw GJ. 2007b. Cytoplasmic domain requirements for Frazzled-mediated attractive axon turning at the Drosophila midline. Development 134: 4325-4334.

Garcia MC, Abbasi M, Singh S, He Q. 2007. Role of Drosophila gene dunc-115 in nervous system. Invert Neurosci 7: $119-128$

Garvalov BK, Flynn KC, Neukirchen D, Meyn L, Teusch N, Wu X, Brakebusch C, Bamburg JR, Bradke F. 2007. Cdc42 regulates cofilin during the establishment of neuronal polarity. J Neurosci 27: 13117-13129.

Geraldo S, Khanzada UK, Parsons M, Chilton JK, GordonWeeks PR. 2008. Targeting of the F-actin-binding protein drebrin by the microtubule plus-tip protein EB3 is required for neuritogenesis. Nat Cell Biol 10: 1181-1189.

Gertler FB, Comer AR, Juang JL, Ahern SM, Clark MJ, Liebl EC, Hoffmann FM. 1995. enabled, a dosage-sensitive suppressor of mutations in the Drosophila Abl tyrosine kinase, encodes an Abl substrate with $\mathrm{SH} 3$ domainbinding properties. Genes Dev 9: 521-533.

Gertler FB, Bennett RL, Clark MJ, Hoffmann FM. 1989. Drosophila abl tyrosine kinase in embryonic CNS axons: a role in axonogenesis is revealed through dosagesensitive interactions with disabled. Cell 58: 103-113.

Gertler FB, Doctor JS, Hoffmann FM. 1990. Genetic suppression of mutations in the Drosophila abl protooncogene homolog. Science 248: 857-860.

Gertler FB, Niebuhr K, Reinhard M, Wehland J, Soriano P. 1996. Mena, a relative of VASP and Drosophila Enabled, is implicated in the control of microfilament dynamics. Cell 87: 227-239.

Ghosh M, Song X, Mouneimne G, Sidani M, Lawrence DS, Condeelis JS. 2004. Cofilin promotes actin polymerization and defines the direction of cell motility. Science 304: 743-746.

Gitai Z, Yu TW, Lundquist EA, Tessier-Lavigne M, Bargmann CI. 2003. The netrin receptor UNC-40/DCC stimulates axon attraction and outgrowth through enabled and, in parallel, Rac and UNC-115/AbLIM. Neuron 37: 53-65.

Goldberg DJ, Burmeister DW. 1986. Stages in axon formation: observations of growth of Aplysia axons in culture 


\section{E.W. Dent et al.}

using video-enhanced contrast-differential interference contrast microscopy. J Cell Biol 103: 1921-1931.

Gonzalez-Agosti C, Solomon F. 1996. Response of radixin to perturbations of growth cone morphology and motility in chick sympathetic neurons in vitro. Cell Motil Cytoskeleton 34: 122-136.

Gonzalez-Billault C, Avila J, Caceres A. 2001. Evidence for the role of MAP1B in axon formation. Mol Biol Cell 12: 2087-2098.

Goode BL, Eck MJ. 2007. Mechanism and function of formins in the control of actin assembly. Annu Rev Biochem 76: 593-627.

Goslin K, Birgbauer E, Banker G, Solomon F. 1989. The role of cytoskeleton in organizing growth cones: a microfilament-associated growth cone component depends upon microtubules for its localization. J Cell Biol 109: $1621-1631$.

Grabham PW, Seale GE, Bennecib M, Goldberg DJ, Vallee RB. 2007. Cytoplasmic dynein and LIS1 are required for microtubule advance during growth cone remodeling and fast axonal outgrowth. J Neurosci 27: 5823-5834.

Grevengoed EE, Loureiro JJ, Jesse TL, Peifer M. 2001. Abelson kinase regulates epithelial morphogenesis in Drosophila. J Cell Biol 155: 1185-1198.

Grevengoed EE, Fox DT, Gates J, Peifer M. 2003. Balancing different types of actin polymerization at distinct sites: roles for Abelson kinase and Enabled. J Cell Biol 163: 1267-1279.

Grosse R, Copeland JW, Newsome TP, Way M, Treisman R. 2003. A role for VASP in RhoA-Diaphanous signalling to actin dynamics and SRF activity. Embo J 22: 3050-3061.

Halloran MC, Kalil K. 1994. Dynamic behaviors of growth cones extending in the corpus callosum of living cortical brain slices observed with video microscopy. J Neurosci 14: $2161-2177$.

Harbott LK, Nobes CD. 2005. A key role for Abl family kinases in EphA receptor-mediated growth cone collapse. Mol Cell Neurosci 30: 1-11.

He Q, Dent EW, Meiri KF. 1997. Modulation of actin filament behavior by GAP-43 (neuromodulin) is dependent on the phosphorylation status of serine 41 , the protein kinase C site. J Neurosci 17: 3515-3524.

Hedgecock EM, Culotti JG, Thomson JN, Perkins LA. 1985. Axonal guidance mutants of Caenorhabditis elegans identified by filling sensory neurons with fluorescein dyes. Dev Biol 111: 158-170.

Henkemeyer M, West S, Gertler F. 1990. A novel tyrosine kinase-independent function of Drosophila abl correlates with proper subcellular localization. Cell 63: 949960.

Higgs HN. 2005. Formin proteins: a domain-based approach. Trends Biochem Sci 30: 342-353.

Higgs HN, Peterson KJ. 2005. Phylogenetic analysis of the formin homology 2 domain. Mol Biol Cell 16: 1-13.

Hines JH, Abu-Rub M, Henley JR. 2010. Asymmetric endocytosis and remodeling of beta(1)-integrin adhesions during growth cone chemorepulsion by MAG. Nat Neurosci 13: $829-837$.

Homem CC, Peifer M. 2009. Exploring the roles of diaphanous and enabled activity in shaping the balance between filopodia and lamellipodia. Mol Biol Cell 20: 5138-5155.
Homma N, Takei Y, Tanaka Y, Nakata T, Terada S, Kikkawa M, Noda Y, Hirokawa N. 2003. Kinesin superfamily protein 2A (KIF2A) functions in suppression of collateral branch extension. Cell 114: 229-239.

Hotulainen P, Llano O, Smirnov S, Tanhuanpaa K, Faix J, Rivera C, Lappalainen P. 2009. Defining mechanisms of actin polymerization and depolymerization during dendritic spine morphogenesis. J Cell Biol 185: 323-339.

Hsouna A, Kim YS, VanBerkum MF. 2003. Abelson tyrosine kinase is required to transduce midline repulsive cues. J Neurobiol 57: 15-30.

Hummel T, Schimmelpfeng K, Klambt C. 1999. Commissure formation in the embryonic CNS of Drosophila. Development 126: 771-779.

Hubberstey AV, Mottillo EP. 2002. Cyclase-associated proteins: CAPacity for linking signal transduction and actin polymerization. FASEB J 16: 487-499.

Hulsmeier J, Pielage J, Rickert C, Technau GM, Klambt C, Stork T. 2007. Distinct functions of alpha-Spectrin and beta-Spectrin during axonal pathfinding. Development 134: $713-722$

Hung RJ, Yazdani U, Yoon J, Wu H, Yang T, Gupta N, Huang Z, van Berkel WJ, Terman JR. 2010. Mical links semaphorins to F-actin disassembly. Nature 463: 823-827.

Ichetovkin I, Grant W, Condeelis J. 2002. Cofilin produces newly polymerized actin filaments that are preferred for dendritic nucleation by the Arp2/3 complex. Curr Biol 12: $79-84$

Jimenez-Mateos EM, Paglini G, Gonzalez-Billault C, Caceres A, Avila J. 2005. End binding protein-1 (EB1) complements microtubule-associated protein-1B during axonogenesis. J Neurosci Res 80: 350-359.

Jurney WM, Gallo G, Letourneau PC, McLoon SC. 2002. Rac1-mediated endocytosis during ephrin-A2- and semaphorin 3A-induced growth cone collapse. J Neurosci 22: 6019-6028.

Kaiser DA, Vinson VK, Murphy DB, Pollard TD. 1999. Profilin is predominantly associated with monomeric actin in Acanthamoeba. J Cell Sci 112: 3779-3790.

Karabay A, Yu W, Solowska JM, Baird DH, Baas PW. 2004. Axonal growth is sensitive to the levels of katanin, a protein that severs microtubules. J Neurosci 24: 5778-5788.

Kaufmann N, Wills ZP, Van Vactor D. 1998. Drosophila Racl controls motor axon guidance. Development 125: 453-461.

Kim YS, Fritz JL, Seneviratne AK, VanBerkum MF. 2002. Constitutively active myosin light chain kinase alters axon guidance decisions in Drosophila embryos. Dev Biol 249: 367-381.

Knoll B, Kretz O, Fiedler C, Alberti S, Schutz G, Frotscher M, Nordheim A. 2006. Serum response factor controls neuronal circuit assembly in the hippocampus. Nat Neurosci 9: 195-204.

Knoll B, Nordheim A. 2009. Functional versatility of transcription factors in the nervous system: the SRF paradigm. Trends Neurosci 32: 432-442.

Koester MP, Muller O, Pollerberg GE. 2007. Adenomatous polyposis coli is differentially distributed in growth cones and modulates their steering. $J$ Neurosci 27: $12590-$ 12600 . 
Kolpak AL, Jiang J, Guo D, Standley C, Bellve K, Fogarty K, Bao Z-Z. 2009. Negative Guidance Factor-Induced Macropinocytosis in the Growth Cone Plays a Critical Role in Repulsive Axon Turning. J Neurosci 29: 10488-10498.

Koizumi H, Tanaka T, Gleeson JG. 2006. Doublecortin-like kinase functions with doublecortin to mediate fiber tract decussation and neuronal migration. Neuron 49: 55-66.

Korobova F, Svitkina T. 2008. Arp2/3 complex is important for filopodia formation, growth cone motility, and neuritogenesis in neuronal cells. Mol Biol Cell 19: 1561-1574.

Krause M, Leslie JD, Stewart M, Lafuente EM, Valderrama F, Jagannathan R, Strasser GA, Rubinson DA, Liu H, Way M, et al. 2004. Lamellipodin, an Ena/VASP ligand, is implicated in the regulation of lamellipodial dynamics. Dev Cell 7: 571-583.

Kruger K, Tam AS, Lu C, Sretavan DW. 1998. Retinal ganglion cell axon progression from the optic chiasm to initiate optic tract development requires cell autonomous function of GAP-43. J Neurosci 18: 5692-5705.

Kubo T, Endo M, Hata K, Taniguchi J, Kitajo K, Tomura S, Yamaguchi A, Mueller BK, Yamashita T. 2008. Myosin IIA is required for neurite outgrowth inhibition produced by repulsive guidance molecule. J Neurochem 105: 113-126.

Lafont F, Rouget M, Rousselet A, Valenza C, Prochiantz A. 1993. Specific responses of axons and dendrites to cytoskeleton perturbations: an in vitro study. J Cell Sci 104: 433-443.

Lanier LM, Gates MA, Witke W, Menzies AS, Wehman AM, Macklis JD, Kwiatkowski D, Soriano P, Gertler FB. 1999. Mena is required for neurulation and commissure formation. Neuron 22: 313-325.

Lebrand C, Dent EW, Strasser GA, Lanier LM, Krause M, Svitkina TM, Borisy GG, Gertler FB. 2004. Critical role of Ena/VASP proteins for filopodia formation in neurons and in function downstream of netrin-1. Neuron 42: $37-49$.

Lee AC, Suter DM. 2008. Quantitative analysis of microtubule dynamics during adhesion-mediated growth cone guidance. Dev Neurobiol 68: 1363-1377.

Lee H, Engel U, Rusch J, Scherrer S, Sheard K, Van Vactor D. 2004. The microtubule plus end tracking protein Orbit/ MAST/CLASP acts downstream of the tyrosine kinase Abl in mediating axon guidance. Neuron 42: 913-926.

Lee S, Nahm M, Lee M, Kwon M, Kim E, Zadeh AD, Cao H, Kim HJ, Lee ZH, Oh SB, et al. 2007. The F-actinmicrotubule crosslinker Shot is a platform for Krasavietzmediated translational regulation of midline axon repulsion. Development 134: 1767-1777.

Li W, Herman RK, Shaw JE. 1992. Analysis of the Caenorhabditis elegans axonal guidance and outgrowth gene unc-33. Genetics 132: 675-689.

Li YH, Ghavampur S, Bondallaz P, Will L, Grenningloh G, Puschel AW. 2009. Rnd1 regulates axon extension by enhancing the microtubule destabilizing activity of SCG10. J Biol Chem 284: 363-371.

Liebl EC, Forsthoefel DJ, Franco LS, Sample SH, Hess JE, Cowger JA, Chandler MP, Shupert AM, Seeger MA. 2000. Dosage-sensitive, reciprocal genetic interactions between the Abl tyrosine kinase and the putative GEF trio reveal trio's role in axon pathfinding. Neuron 26: $107-118$.
Liebl EC, Rowe RG, Forsthoefel DJ, Stammler AL, Schmidt ER, Turski M, Seeger MA. 2003. Interactions between the secreted protein Amalgam, its transmembrane receptor Neurotactin and the Abelson tyrosine kinase affect axon pathfinding. Development 130: 3217-3226.

Lin CH, Espreafico EM, Mooseker MS, Forscher P. 1996. Myosin drives retrograde F-actin flow in neuronal growth cones. Neuron 16: 769-782.

Lin CH, Forscher P. 1993. Cytoskeletal remodeling during growth cone-target interactions. J Cell Biol 121: 13691383.

Lin CH, Forscher P. 1995. Growth cone advance is inversely proportional to retrograde F-actin flow. Neuron 14: 763-771.

Lin TY, Huang CH, Kao HH, Liou GG, Yeh SR, Cheng CM, Chen MH, Pan RL, Juang JL. 2009. Abi plays an opposing role to Abl in Drosophila axonogenesis and synaptogenesis. Development 136: 3099-3107.

Liu W, Sato A, Khadka D, Bharti R, Diaz H, Runnels LW, Habas R. 2008. Mechanism of activation of the Formin protein Daam1. Proc Natl Acad Sci U S A 105: 210-215.

Loudon RP, Silver LD, Yee HF, Gallo G. 2006. RhoA-kinase and myosin II are required for the maintenance of growth cone polarity and guidance by nerve growth factor. J Neurobiol 66: 847-867.

Loureiro J, Peifer M. 1998. Roles of Armadillo, a Drosophila catenin, during central nervous system development. Curr Biol 8: 622-632.

Lowery LA, Lee H, Lu C, Murphy R, Obar RA, Zhai B, Schedl M, Van Vactor D, Zhan Y. 2010. Parallel Genetic and Proteomic Screens Identify Msps as a CLASP-Abl Pathway Interactor in Drosophila. Genetics: 101534/ genetics1110115626.

Lowery LA, Van Vactor D. 2009. The trip of the tip: understanding the growth cone machinery. Nat Rev Mol Cell Biol 10: 332-343.

Lu C, Huang X, Ma HF, Gooley JJ, Aparacio J, Roof DJ, Chen C, Chen DF, Li T. 2003. Normal retinal development and retinofugal projections in mice lacking the retina-specific variant of actin-binding LIM domain protein. Neuroscience 120: 121-131.

Lu M, Witke W, Kwiatkowski DJ, Kosik KS. 1997. Delayed retraction of filopodia in gelsolin null mice. J Cell Biol 138: $1279-1287$.

Lundquist EA, Herman RK, Shaw JE, Bargmann CI. 1998. UNC-115, a conserved protein with predicted LIM and actin-binding domains, mediates axon guidance in C. elegans. Neuron 21: 385-392.

Maciver SK, Pope BJ, Whytock S, Weeds AG. 1998. The effect of two actin depolymerizing factors (ADF/cofilins) on actin filament turnover: $\mathrm{pH}$ sensitivity of F-actin binding by human $\mathrm{ADF}$, but not of Acanthamoeba actophorin. Eur J Biochem 256: 388-397.

Mack TG, Koester MP, Pollerberg GE. 2000. The microtubule-associated protein MAP1B is involved in local stabilization of turning growth cones. Mol Cell Neurosci 15: 51-65.

Maier DL, Mani S, Donovan SL, Soppet D, Tessarollo L, McCasland JS, Meiri KF. 1999. Disrupted cortical map and absence of cortical barrels in growth-associated 
E.W. Dent et al.

protein (GAP)-43 knockout mice. Proc Natl Acad Sci U S A 96: 9397-9402.

Mallavarapu A, Mitchison T. 1999. Regulated actin cytoskeleton assembly at filopodium tips controls their extension and retraction. J Cell Biol 146: 1097-1106.

Marsh L, Letourneau PC. 1984. Growth of neurites without filopodial or lamellipodial activity in the presence of cytochalasin B. J Cell Biol 99: 2041-2047.

Marsick BM, Flynn KC, Santiago-Medina M, Bamburg JR, Letourneau PC. 2010. Activation of ADF/cofilin mediates attractive growth cone turning toward nerve growth factor and netrin-1. Dev Neurobiol 70: 565-588.

Martinez-Lopez MJ, Alcantara S, Mascaro C, Perez-Branguli F, Ruiz-Lozano P, Maes T, Soriano E, Buesa C. 2005. Mouse neuron navigator 1 , a novel microtubule-associated protein involved in neuronal migration. Mol Cell Neurosci 28: 599-612.

Matusek T, Gombos R, Szecsenyi A, Sanchez-Soriano N, Czibula A, Pataki C, Gedai A, Prokop A, Rasko I, Mihaly J. 2008. Formin proteins of the DAAM subfamily play a role during axon growth. J Neurosci 28: 13310-13319.

McGough A, Pope B, Chiu W, Weeds A. 1997. Cofilin changes the twist of F-actin: implications for actin filament dynamics and cellular function. J Cell Biol 138: $771-781$.

McLaughlin T, Hindges R, O'Leary DD. 2003. Regulation of axial patterning of the retina and its topographic mapping in the brain. Curr Opin Neurobiol 13: 57-69.

Medeiros NA, Burnette DT, Forscher P. 2006. Myosin II functions in actin-bundle turnover in neuronal growth cones. Nat Cell Biol 8: 215-226.

Meixner A, Haverkamp S, Wassle H, Fuhrer S, Thalhammer J, Kropf N, Bittner RE, Lassmann H, Wiche G, Propst F. 2000. MAP1B is required for axon guidance and Is involved in the development of the central and peripheral nervous system. J Cell Biol 151: 1169-1178.

Menna E, Disanza A, Cagnoli C, Schenk U, Gelsomino G, Frittoli E, Hertzog M, Offenhauser N, Sawallisch C, Kreienkamp H-J, et al. 2009. Eps8 regulates axonal filopodia in hippocampal neurons in response to brain-derived neurotrophic factor (BDNF). PLoS Biol 7: e1000138.

Menzies AS, Aszodi A, Williams SE, Pfeifer A, Wehman AM, Goh KL, Mason CA, Fassler R, Gertler FB. 2004. Mena and vasodilator-stimulated phosphoprotein are required for multiple actin-dependent processes that shape the vertebrate nervous system. J Neurosci 24: 8029-8038.

Michael M, Vehlow A, Navarro C, Krause M. 2010. c-Abl, Lamellipodin, and Ena/VASP proteins cooperate in dorsal ruffling of fibroblasts and axonal morphogenesis. Curr Biol 20: 783-791.

Mintz CD, Carcea I, McNickle DG, Dickson TC, Ge Y, Salton SR, Benson DL. 2008. ERM proteins regulate growth cone responses to Sema3A. J Comp Neurol 510: 351-366.

Moore SW, Tessier-Lavigne M, Kennedy TE. 2007. Netrins and their receptors. Adv Exp Med Biol 621: 17-31.

Moresco EM, Donaldson S, Williamson A, Koleske AJ. 2005. Integrin-mediated dendrite branch maintenance requires Abelson (Abl) family kinases. J Neurosci 25: 6105-6118.

Morii H, Shiraishi-Yamaguchi Y, Mori N. 2006. SCG10, a microtubule destabilizing factor, stimulates the neurite outgrowth by modulating microtubule dynamics in rat hippocampal primary cultured neurons. J Neurobiol 66: 1101-1114.

Mouneimne G, Soon L, DesMarais V, Sidani M, Song X, Yip S-C, Ghosh M, Eddy R, Backer JM, Condeelis J. 2004. Phospholipase $\mathrm{C}$ and cofilin are required for carcinoma cell directionality in response to EGF stimulation. J Cell Biol 166: 697-708.

Murray A, Naeem A, Barnes SH, Drescher U, Guthrie S. 2010. Slit and Netrin-1 guide cranial motor axon pathfinding via Rho-kinase, myosin light chain kinase and myosin II. Neural Dev 5: 16.

Myers KA, Tint I, Nadar CV, He Y, Black MM, Baas PW. 2006. Antagonistic forces generated by cytoplasmic dynein and myosin-II during growth cone turning and axonal retraction. Traffic 7: 1333-1351.

Nadar VC, Ketschek A, Myers KA, Gallo G, Baas PW. 2008. Kinesin-5 is essential for growth-cone turning. Curr Biol 18: $1972-1977$.

Nedrelow JH, Cianci CD, Morrow JS. 2003. c-Src binds alpha II spectrin's Src homology 3 (SH3) domain and blocks calpain susceptibility by phosphorylating Tyr1176. J Biol Chem 278: 7735-7741.

$\mathrm{Ng}$ J, Luo L. 2004. Rho GTPases regulate axon growth through convergent and divergent signaling pathways. Neuron 44: 779-793.

Niebuhr K, Ebel F, Frank R, Reinhard M, Domann E, Carl UD, Walter U, Gertler FB, Wehland J, Chakraborty T. 1997. A novel proline-rich motif present in ActA of Listeria monocytogenes and cytoskeletal proteins is the ligand for the EVH1 domain, a protein module present in the Ena/VASP family. EMBO J 16: 5433-5444.

Noiges R, Eichinger R, Kutschera W, Fischer I, Nemeth Z, Wiche G, Propst F. 2002. Microtubule-associated protein 1A (MAP1A) and MAP1B: light chains determine distinct functional properties. J Neurosci 22: 2106-2114.

Norris AD, Dyer JO, Lundquist EA. 2009. The Arp2/3 complex, UNC-115/abLIM, and UNC-34/Enabled regulate axon guidance and growth cone filopodia formation in Caenorhabditis elegans. Neural Dev 4: 38.

Otsuka AJ, Franco R, Yang B, Shim KH, Tang LZ, Zhang YY, Boontrakulpoontawee P, Jeyaprakash A, Hedgecock E, Wheaton VI, et al. 1995. An ankyrin-related gene (unc-44) is necessary for proper axonal guidance in Caenorhabditis elegans. J Cell Biol 129: 1081-1092.

Paglini G, Kunda P, Quiroga S, Kosik K, Caceres A. 1998. Suppression of radixin and moesin alters growth cone morphology, motility, and process formation in primary cultured neurons. J Cell Biol 143: 443-455.

Pak CW, Flynn KC, Bamburg JR. 2008. Actin-binding proteins take the reins in growth cones. Nat Rev Neurosci 9: 136- 147 .

Pasic L, Kotova TI, Schafer DA. 2008. Ena/VASP proteins capture actin filament barbed ends. J Biol Chem 283: 9814-9819.

Phillis R, Statton D, Caruccio P, Murphey RK. 1996. Mutations in the $8 \mathrm{kDa}$ dynein light chain gene disrupt sensory axon projections in the Drosophila imaginal CNS. Development 122: 2955-2963.

Pinyol R, Haeckel A, Ritter A, Qualmann B, Kessels MM. 2007. Regulation of N-WASP and the Arp2/3 complex 
by Abp1 controls neuronal morphology. PLoS ONE 2: e400.

Piper M, Anderson R, Dwivedy A, Weinl C, van Horck F, Leung KM, Cogill E, Holt C. 2006. Signaling mechanisms underlying Slit2-induced collapse of Xenopus retinal growth cones. Neuron 49: 215-228.

Pollard TD, Borisy GG. 2003. Cellular motility driven by assembly and disassembly of actin filaments. Cell 112: 453-465.

Pollard TD, Cooper JA. 2009. Actin, a central player in cell shape and movement. Science 326: 1208-1212.

Posern G, Treisman R. 2006. Actin' together: serum response factor, its cofactors and the link to signal transduction. Trends Cell Biol 16: 588-596.

Poulain FE, Sobel A. 2007. The "SCG10-LIke Protein" SCLIP is a novel regulator of axonal branching in hippocampal neurons, unlike SCG10. Mol Cell Neurosci 34: 137-146.

Purro SA, Ciani L, Hoyos-Flight M, Stamatakou E, Siomou E, Salinas PC. 2008. Wnt regulates axon behavior through changes in microtubule growth directionality: a new role for adenomatous polyposis coli. J Neurosci 28: 8644-8654.

Qiang L, Yu W, Liu M, Solowska JM, Baas PW. 2009. Basic fibroblast growth factor elicits formation of interstitial axonal branches via enhanced severing of microtubules. Mol Biol Cell 21: 334-344.

Quinn CC, Chen E, Kinjo TG, Kelly G, Bell AW, Elliott RC, McPherson PS, Hockfield S. 2003. TUC-4b, a novel TUC family variant, regulates neurite outgrowth and associates with vesicles in the growth cone. $J$ Neurosci 23: 2815-2823.

Quinn CC, Pfeil DS, Chen E, Stovall EL, Harden MV, Gavin MK, Forrester WC, Ryder EF, Soto MC, Wadsworth WG. 2006. UNC-6/netrin and SLT-1/slit guidance cues orient axon outgrowth mediated by MIG-10/RIAM/lamellipodin. Curr Biol 16: 845-853.

Quinn CC, Pfeil DS, Wadsworth WG. 2008. CED-10/Racl mediates axon guidance by regulating the asymmetric distribution of MIG-10/lamellipodin. Curr Biol 18: 808-813.

Riano E, Martignoni M, Mancuso G, Cartelli D, Crippa F, Toldo I, Siciliano G, Di Bella D, Taroni F, Bassi MT, et al. 2009. Pleiotropic effects of spastin on neurite growth depending on expression levels. J Neurochem 108: 1277-1288.

Rothenberg ME, Rogers SL, Vale RD, Jan LY, Jan YN. 2003. Drosophila pod-1 crosslinks both actin and microtubules and controls the targeting of axons. Neuron 39: 779-791.

Sabry JH, O'Connor TP, Evans L, Toroian-Raymond A, Kirschner M, Bentley D. 1991. Microtubule behavior during guidance of pioneer neuron growth cones in situ. J Cell Biol 115: 381-395.

Sanchez-Soriano N, Travis M, Dajas-Bailador F, GoncalvesPimentel C, Whitmarsh AJ, Prokop A. 2009. Mouse ACF7 and drosophila short stop modulate filopodia formation and microtubule organisation during neuronal growth. J Cell Sci 122: 2534-2542.

Sarmiere PD, Bamburg JR. 2004. Regulation of the neuronal actin cytoskeleton by ADF/cofilin. J Neurobiol 58: $103-117$.
Sasaki Y, Hayashi K, Shirao T, Ishikawa R, Kohama K. 1996. Inhibition by drebrin of the actin-bundling activity of brain fascin, a protein localized in filopodia of growth cones. J Neurochem 66: 980-988.

Schaefer AW, Schoonderwoert VT, Ji L, Mederios N, Danuser G, Forscher P. 2008. Coordination of actin filament and microtubule dynamics during neurite outgrowth. Dev Cell 15: 146-162.

Schirenbeck A, Arasada R, Bretschneider T, Stradal TE, Schleicher M, Faix J. 2006. The bundling activity of vasodilator-stimulated phosphoprotein is required for filopodium formation. Proc Natl Acad Sci U S A 103: 7694-7699.

Schlatter MC, Buhusi M, Wright AG, Maness PF. 2008. CHL1 promotes Sema3A-induced growth cone collapse and neurite elaboration through a motif required for recruitment of ERM proteins to the plasma membrane. J Neurochem 104: 731-744.

Schumacher N, Borawski JM, Leberfinger CB, Gessler M, Kerkhoff E. 2004. Overlapping expression pattern of the actin organizers Spir-1 and formin-2 in the developing mouse nervous system and the adult brain. Gene Expr Patterns 4: 249-255.

Shakir MA, Jiang K, Struckhoff EC, Demarco RS, Patel FB, Soto MC, Lundquist EA. 2008. The Arp2/3 activators WAVE and WASP have distinct genetic interactions with Rac GTPases in Caenorhabditis elegans axon guidance. Genetics 179: 1957-1971.

Shekarabi M, Kennedy TE. 2002. The netrin-1 receptor DCC promotes filopodia formation and cell spreading by activating Cdc42 and Rac1. Mol Cell Neurosci 19: $1-17$.

Shekarabi M, Moore SW, Tritsch NX, Morris SJ, Bouchard JF, Kennedy TE. 2005. Deleted in colorectal cancer binding netrin-1 mediates cell substrate adhesion and recruits Cdc42, Rac1, Pak1, and N-WASP into an intracellular signaling complex that promotes growth cone expansion. J Neurosci 25: 3132-3141.

Shen Y, Mani S, Donovan SL, Schwob JE, Meiri KF. 2002. Growth-associated protein- 43 is required for commissural axon guidance in the developing vertebrate nervous system. J Neurosci 22: 239-247.

Shi SH, Cheng T, Jan LY, Jan YN. 2004. APC and GSK-3beta are involved in mPar3 targeting to the nascent axon and establishment of neuronal polarity. Curr Biol 14: 2025-2032.

Shintani T, Ihara M, Tani S, Sakuraba J, Sakuta H, Noda M. 2009. APC2 plays an essential role in axonal projections through the regulation of microtubule stability. J Neurosci 29: 11628-11640.

Smith K, Humphreys D, Hume PJ, Koronakis V. 2010. Enteropathogenic Escherichia coli recruits the cellular inositol phosphatase SHIP2 to regulate actin-pedestal formation. Cell Host Microbe 7: 13-24.

Stern S, Debre E, Stritt C, Berger J, Posern G, Knoll B. 2009. A nuclear actin function regulates neuronal motility by serum response factor-dependent gene transcription. J Neurosci 29: 4512-4518.

Strasser G, Rahim N, VanderWaal K, Gertler F, Lanier L. 2004. Arp $2 / 3$ is a negative regulator of growth cone translocation. Neuron 43: 81-94. 
E.W. Dent et al.

Strittmatter SM, Fankhauser C, Huang PL, Mashimo H, Fishman MC. 1995. Neuronal pathfinding is abnormal in mice lacking the neuronal growth cone protein GAP-43. Cell 80: 445-452.

Struckhoff EC, Lundquist EA. 2003. The actin-binding protein UNC-115 is an effector of Rac signaling during axon pathfinding in C. elegans. Development 130: 693-704.

Suh LH, Oster SF, Soehrman SS, Grenningloh G, Sretavan DW. 2004. L1/Laminin modulation of growth cone response to EphB triggers growth pauses and regulates the microtubule destabilizing protein SCG10. J Neurosci 24: 1976-1986.

Sun HQ, Yamamoto M, Mejillano M, Yin HL. 1999. Gelsolin, a multifunctional actin regulatory protein. J Biol Chem 274: 33179-33182.

Suter DM, Errante LD, Belotserkovsky V, Forscher P. 1998. The Ig superfamily cell adhesion molecule, apCAM, mediates growth cone steering by substrate-cytoskeletal coupling. J Cell Biol 141: 227-240.

Suter DM, Forscher P. 2000. Substrate-cytoskeletal coupling as a mechanism for the regulation of growth cone motility and guidance. J Neurobiol 44: 97-113.

Suter DM, Forscher P. 2001. Transmission of growth cone traction force through apCAM-cytoskeletal linkages is regulated by Src family tyrosine kinase activity. J Cell Biol 155: 427-438.

Suter DM, Schaefer AW, Forscher P. 2004. Microtubule dynamics are necessary for SRC family kinase-dependent growth cone steering. Curr Biol 14: 1194-1199.

Symons MH, Mitchison TJ. 1991. Control of actin polymerization in live and permeabilized fibroblasts. J Cell Biol 114: $503-513$.

Tahirovic S, Hellal F, Neukirchen D, Hindges R, Garvalov BK, Flynn KC, Stradal TE, Chrostek-Grashoff A, Brakebusch C, Bradke F. 2010. Rac1 regulates neuronal polarization through the WAVE complex. J Neurosci 30: 6930-6943.

Takahashi M, Yamagata M, Noda M. 1999. Specific expression of ezrin, a cytoskeletal-membrane linker protein, in a subset of chick retinotectal and sensory projections. Eur J Neurosci 11: 545-558.

Takei Y, Teng J, Harada A, Hirokawa N. 2000. Defects in axonal elongation and neuronal migration in mice with disrupted tau and maplb genes. J Cell Biol 150: 989-1000.

Tanaka E, Kirschner MW. 1995. The role of microtubules in growth cone turning at substrate boundaries. J Cell Biol 128: $127-137$.

Tararuk T, Ostman N, Li W, Bjorkblom B, Padzik A, Zdrojewska J, Hongisto V, Herdegen T, Konopka W, Courtney MJ, et al. 2006. JNK1 phosphorylation of SCG10 determines microtubule dynamics and axodendritic length. J Cell Biol 173: 265-277.

Tepass U. 2009. FERM proteins in animal morphogenesis. Curr Opin Genet Dev 19: 357-367.

Terman JR, Mao T, Pasterkamp RJ, Yu HH, Kolodkin AL. 2002. MICALs, a family of conserved flavoprotein oxidoreductases, function in plexin-mediated axonal repulsion. Cell 109: 887-900.

Togel M, Wiche G, Propst F. 1998. Novel features of the light chain of microtubule-associated protein MAP1B: microtubule stabilization, self interaction, actin filament binding, and regulation by the heavy chain. J Cell Biol 143: 695-707.

Tojima T, Akiyama H, Itofusa R, Li Y, Katayama H, Miyawaki A, Kamiguchi H. 2007. Attractive axon guidance involves asymmetric membrane transport and exocytosis in the growth cone. Nat Neurosci 10: 58-66.

Tojima T, Itofusa R, Kamiguchi H. 2010. Asymmetric clathrin-mediated endocytosis drives repulsive growth cone guidance. Neuron 66: 370-377.

Tsai JW, Chen Y, Kriegstein AR, Vallee RB. 2005. LIS1 RNA interference blocks neural stem cell division, morphogenesis, and motility at multiple stages. J Cell Biol 170: $935-945$.

Vactor DV, Sink H, Fambrough D, Tsoo R, Goodman CS. 1993. Genes that control neuromuscular specificity in Drosophila. Cell 73: 1137-1153.

Vicente-Manzanares M, Ma X, Adelstein RS, Horwitz AR. 2009. Non-muscle myosin II takes centre stage in cell adhesion and migration. Nat Rev Mol Cell Biol 10: 778-790.

Vignjevic D, Kojima S, Aratyn Y, Danciu O, Svitkina T, Borisy GG. 2006. Role of fascin in filopodial protrusion. J Cell Biol 174: 863-875.

Wang W, Eddy R, Condeelis J. 2007. The cofilin pathway in breast cancer invasion and metastasis. Nat Rev Cancer 7: 429-440.

Wen Z, Han L, Bamburg JR, Shim S, Ming GL, Zheng JQ. 2007. BMP gradients steer nerve growth cones by a balancing act of LIM kinase and Slingshot phosphatase on ADF/cofilin. J Cell Biol 178: 107-119.

Williams JA, MacIver B, Klipfell EA, Thomas GH. 2004. The C-terminal domain of Drosophila (beta) heavy-spectrin exhibits autonomous membrane association and modulates membrane area. J Cell Sci 117: 771-782.

Williamson T, Gordon-Weeks PR, Schachner M, Taylor J. 1996. Microtubule reorganization is obligatory for growth cone turning. Proc Natl Acad Sci U S A 93: 15221-15226.

Wills Z, Bateman J, Korey CA, Comer A, Van Vactor D. 1999a. The tyrosine kinase Abl and its substrate enabled collaborate with the receptor phosphatase Dlar to control motor axon guidance. Neuron 22: 301-312.

Wills Z, Emerson M, Rusch J, Bikoff J, Baum B, Perrimon N, Van Vactor D. 2002. A Drosophila homolog of cyclaseassociated proteins collaborates with the Abl tyrosine kinase to control midline axon pathfinding. Neuron 36: 611-622.

Wills Z, Marr L, Zinn K, Goodman CS, Van Vactor D. 1999b. Profilin and the Abl tyrosine kinase are required for motor axon outgrowth in the Drosophila embryo. Neuron 22: 291-299.

Wood JD, Landers JA, Bingley M, McDermott CJ, ThomasMcArthur V, Gleadall LJ, Shaw PJ, Cunliffe VT. 2006. The microtubule-severing protein Spastin is essential for axon outgrowth in the zebrafish embryo. Hum Mol Genet 15: 2763-2771.

Xu J, Casella JF, Pollard TD. 1999. Effect of capping protein, CapZ, on the length of actin filaments and mechanical properties of actin filament networks. Cell Motil Cytoskeleton 42: 73-81. 
The Growth Cone Cytoskeleton in Axon Outgrowth and Guidance

Yamakita Y, Matsumura F, Yamashiro S. 2009. Fascin1 is dispensable for mouse development but is favorable for neonatal survival. Cell Motil Cytoskeleton 66: 524-534.

Yang Y, Lundquist EA. 2005. The actin-binding protein UNC-115/abLIM controls formation of lamellipodia and filopodia and neuronal morphogenesis in Caenorhabditis elegans. Mol Cell Biol 25: 5158-5170.

Yoshimura T, Kawano Y, Arimura N, Kawabata S, Kikuchi A, Kaibuchi K. 2005. GSK-3beta regulates phosphorylation of CRMP-2 and neuronal polarity. Cell 120: 137-149.

Yu HH, Zisch AH, Dodelet VC, Pasquale EB. 2001. Multiple signaling interactions of $\mathrm{Abl}$ and Arg kinases with the EphB2 receptor. Oncogene 20: 3995-4006.

Yu TW, Hao JC, Lim W, Tessier-Lavigne M, Bargmann CI. 2002. Shared receptors in axon guidance: SAX-3/Robo signals via UNC-34/Enabled and a Netrin-independent UNC-40/DCC function. Nat Neurosci 5: 1147-1154.

Yu W, Qiang L, Solowska JM, Karabay A, Korulu S, Baas PW. 2008. The microtubule-severing proteins spastin and katanin participate differently in the formation of axonal branches. Mol Biol Cell 19: 1485-1498.
Zallen JA, Cohen Y, Hudson AM, Cooley L, Wieschaus E, Schejter ED. 2002. SCAR is a primary regulator of Arp2/3-dependent morphological events in Drosophila. J Cell Biol 156: 689-701.

Zallen JA, Kirch SA, Bargmann CI. 1999. Genes required for axon pathfinding and extension in the C. elegans nerve ring. Development 126: 3679-3692.

Zhang XF, Schaefer AW, Burnette DT, Schoonderwoert VT, Forscher P. 2003. Rho-dependent contractile responses in the neuronal growth cone are independent of classical peripheral retrograde actin flow. Neuron 40: 931-944.

Zhou FQ, Zhou J, Dedhar S, Wu YH, Snider WD. 2004. NGF-induced axon growth is mediated by localized inactivation of GSK-3beta and functions of the microtubule plus end binding protein APC. Neuron 42: 897-912.

Zhu Q, Julien JP. 1999. A key role for GAP-43 in the retinotectal topographic organization. Exp Neurol 155: $228-242$. 


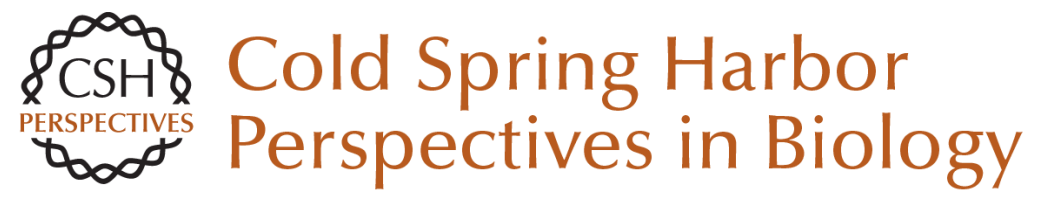

\section{The Growth Cone Cytoskeleton in Axon Outgrowth and Guidance}

Erik W. Dent, Stephanie L. Gupton and Frank B. Gertler

Cold Spring Harb Perspect Biol 2011; doi: 10.1101/cshperspect.a001800 originally published online November 24, 2010

\section{Subject Collection Neuronal Guidance}

Mechanisms and Molecules of Neuronal Wiring: A Primer

Alex L. Kolodkin and Marc Tessier-Lavigne

Guidance Molecules in Axon Pruning and Cell

Death

Pierre Vanderhaeghen and Hwai-Jong Cheng

Initiating and Growing an Axon

F. Polleux and William Snider

Navigating Intermediate Targets: The Nervous System Midline

Barry J. Dickson and Yimin Zou

Cellular Strategies of Axonal Pathfinding

Jonathan Raper and Carol Mason

Guidance Molecules in Axon Regeneration

Roman J. Giger, Edmund R. Hollis II and Mark H. Tuszynski

Signaling from Axon Guidance Receptors Greg J. Bashaw and Rüdiger Klein

Visual Map Development: Bidirectional Signaling, Bifunctional Guidance Molecules, and

Competition

David A. Feldheim and Dennis D. M. O'Leary
Wiring the Brain: The Biology of Neuronal

Guidance

Alain Chédotal and Linda J. Richards

Guidance Molecules in Synapse Formation and

Plasticity Kang Shen and Christopher W. Cowan

The Growth Cone Cytoskeleton in Axon

Outgrowth and Guidance

Erik W. Dent, Stephanie L. Gupton and Frank B. Gertler

Topographic Mapping--The Olfactory System Takeshi Imai, Hitoshi Sakano and Leslie B. Vosshall

Self-avoidance and Tiling: Mechanisms of

Dendrite and Axon Spacing Wesley B. Grueber and Alvaro Sagasti

Trafficking Guidance Receptors Bettina Winckler and Ira Mellman

Axon Guidance Molecules in Vascular Patterning Ralf H. Adams and Anne Eichmann

Human Genetic Disorders of Axon Guidance Elizabeth C. Engle

For additional articles in this collection, see http://cshperspectives.cshlp.org/cgi/collection/

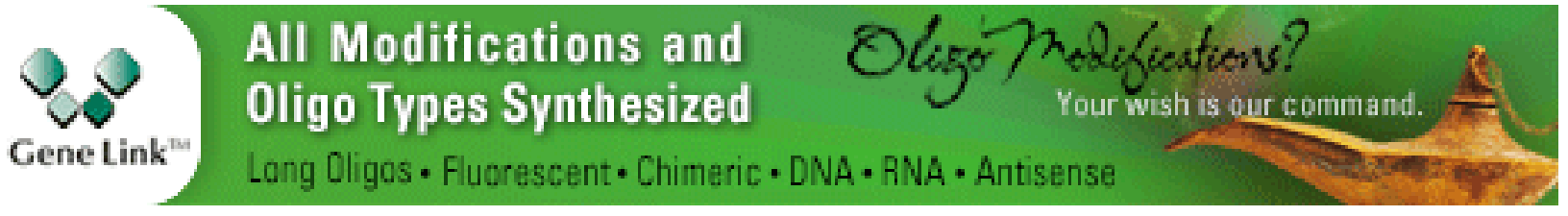

Copyright @ 2011 Cold Spring Harbor Laboratory Press; all rights reserved 